\title{
Cross-sectional vs. longitudinal research: a case study of trees with hollows and marsupials in Australian forests
}

\author{
D. B. Lindenmayer, ${ }^{1,3}$ J. Wood, ${ }^{1,2}$ L. McBurney,${ }^{1}$ D. Michael,${ }^{1}$ M. Crane, ${ }^{1}$ C. MacGregor,${ }^{1}$ \\ R. Montague-Drake, ${ }^{1}$ P. Gibbons, ${ }^{1}$ and S. C. Banks ${ }^{1}$ \\ ${ }^{1}$ Fenner School of Environment and Society, The Australian National University, Canberra, A.C.T. 0200 Australia \\ ${ }^{2}$ Statistical Consulting Unit, The Australian National University, Canberra, A.C.T. 0200 Australia
}

Abstract. How different are insights based on cross-sectional studies from those of longitudinal investigations? We addressed this question using a detailed case study encompassing a rare suite of inter-connected cross-sectional and longitudinal investigations that have spanned the past two decades and included work on: (1) the decay and collapse of large-cavity forest trees (termed "trees with hollows"), (2) populations of a suite of species of arboreal marsupials that are reliant on trees with hollows as nesting and denning sites, and (3) relationships between the abundance, type, and condition of trees with hollows and the presence, abundance, and species richness of these animals. Our case study was from the montane ash eucalypt forests of the Central Highlands of Victoria, southeastern Australia.

Our longitudinal studies led to new insights that either would not have been possible from a cross-sectional study, or which were unexpected because they did not conform, or only partially conformed, to postulated responses made at the outset based on the results of earlier research. These new insights included: (1) a substantial slowing in rates of tree fall between 1997 and 2006, which were significantly lower than predicted from earlier data gathered between 1983 and 1993, (2) no evidence for a decline in populations of almost all species of arboreal marsupials between 1997 and 2007, despite the loss of nearly 14\% of the measured population of trees with hollows during that time, (3) changes in nest tree selection by some species of arboreal marsupials in response to these changes in hollow availability, (4) concentration effects, in which populations of animals used the declining tree hollow resource more intensively, and (5) evidence for significant rainfall effects on temporal changes in animal abundance.

Our case study underscored the additional ecological insights that can be generated from longitudinal studies, including how relationships between biota and their habitat can change over time. Understanding these temporal changes is essential for informed forest management and biodiversity conservation, and points toward the need for greater use of longitudinal data sets in ecology.

Key words: cross-sectional studies; forest management; forest structure; hollow-dependent arboreal marsupials; longitudinal studies; southeastern Australia; trees with hollows; wildlife population dynamics.

\section{INTRODUCTION}

Understanding where organisms occur, and why they occur where they do, is a core part of theoretical and applied ecology (Elton 1927, Levin 2009), and lies at the heart of work quantifying the habitat requirements of particular species (Guisan and Zimmerman 2000, Morrison et al. 2006). Many factors at a range of spatial scales can influence the distribution, abundance, and habitat requirements of species, and an array of different approaches can be used to quantify them (Guisan and Thuiller 2005, Lindenmayer and Burgman 2005). One approach is to use cross-sectional or spacefor-time (snapshot) investigations (Diamond 1986). These take place at a single point in time and use spatially replicated sites to address questions about

Manuscript received 16 February 2011; accepted 5 April 2011. Corresponding Editor: S. R. Beissinger.

${ }^{3}$ E-mail: david.lindenmayer@anu.edu.au temporal processes. Cross-sectional investigations are extremely widespread in ecology. They are prominent in the myriad of studies quantifying the influence of landscape change and habitat fragmentation on the distribution and abundance of biota (McGarigal and Cushman 2002). Cross-sectional studies also dominate other major bodies of ecological work like those examining the effects of fire on plant and animal distribution and abundance (Whelan 1995), and relationships between forest harvesting and the distribution of forest biota (Lindenmayer and Franklin 2002).

Cross-sectional studies can deliver important insights about spatial patterns of distribution and abundance as well as the habitat relationships of organisms. They often can be established relatively cheaply and completed rapidly (Margules and Austin 1991), but robust interpretation of data from cross-sectional studies can be problematic in some instances. These include where: 
(1) there is substantial temporal variability in ecosystem conditions and populations of organisms (Wiens 1981, Fuller et al. 1997, Maron et al. 2005) and there is a prolonged period until expression of key trends (Lindenmayer and Likens 2010), and (2) there are large (but poorly known) differences between sites in environmental history that confound treatment or other effects (Likens 1989, Pickett 1989, Whelan 1995).

Some of these potential limitations can be overcome with longitudinal studies (Likens 1989). Indeed, longitudinal studies are often critical for identifying the ecological processes giving rise to spatial and temporal patterns (Holmes and Sherry 2001, Krebs et al. 2001), such as the causal factors underpinning environmental problems (Lindenmayer and Likens 2010). However, longitudinal studies can be difficult and costly to establish and maintain over prolonged periods of time (Strayer et al. 1986, Lindenmayer and Likens 2010).

Given the advantages and disadvantages of these two broad kinds of studies, it is important to resolve: (1) whether predictions from cross-sectional studies hold when tested with longitudinal data; and (2) what kinds of additional insights longitudinal studies provide over those gained from cross-sectional research. We addressed these issues through a suite of interconnected cross-sectional and longitudinal investigations from the wet montane ash eucalypt forests (see Plate 1) of the Central Highlands of Victoria, southeastern Australia. Our case study was underpinned by a series of investigations that encompassed: (1) temporal changes in a population of large-cavity trees (termed hereafter "trees with hollows") that has been declining over the past 25 years, (2) populations of cavity-dependent arboreal marsupials that are reliant on trees with hollows as nest and den sites, and (3) relationships between the abundance and morphological characteristics of trees with hollows and the presence, abundance, and species richness of arboreal marsupials.

Insights from our cross-sectional and longitudinal work have broad relevance to forest ecosystems and forest wildlife conservation in numerous jurisdictions worldwide. This is because large trees with hollows are a key attribute of vegetation structure in forests globally (Linder and Östlund 1998, Ranius et al. 2009). These trees exhibit strong temporal patterns in occurrence, abundance, and condition (Keen 1955, Cline et al. 1980, Gibbons et al. 2008), and can take a prolonged time ( $>100$ years) to develop (Gibbons and Lindenmayer 2002, Keeton 2006, van Pelt 2007), which is especially problematic if trees are removed en masse as the result of a disturbance event (e.g., stand-replacing wildfire, clear-cut logging) (Lindenmayer and Franklin 2002). Large trees with hollows are also critical nesting and sheltering resources for many animal species in a wide range of ecosystems, up to $30 \%$ of the vertebrate biota depending on the forest type under consideration (Rose et al. 2001, Gibbons and Lindenmayer 2002, Bai and Muhlenberg 2008), and for some groups such as mammals, possibly $>350$ species globally (Nowak 1999). Changes in the abundance of hollow-tree resources may accordingly have a major influence on populations of cavity-dependent biota (Newton 1994, Fenger et al. 2006). Understanding the dynamics of populations of trees with hollows and populations of organisms associated with these trees is therefore a critically important part of ecologically sustainable forest management, and in turn, the successful integration of wood and paper production with biodiversity conservation activities (Hunter 1990, Lindenmayer and Franklin 2002).

\section{Case Study Background, Research Questions, AND HYPOTHESES}

In this section, we briefly outline the results of earlier studies on: (1) temporal changes in populations of trees with hollows, and (2) relationships between the abundance and types of trees with hollows and populations of cavity-dependent animals in the montane ash forests of the Central Highlands of Victoria, southeastern Australia. These studies represent important information upon which our hypotheses were developed and then subsequently tested with longitudinal data.

\section{Hollow-tree resources in montane ash forests}

Fire is the principal natural disturbance in montane ash forest (Ashton 1981), and given that the two dominant overstory tree species in these forests, mountain ash (Eucalyptus regnans) and alpine ash (Eucalyptus delegatensis), are considered to be fire sensitive, wildfires may be stand-replacing events. Young stems belonging to a single age cohort regenerate in areas where older trees are killed by fire (Ashton 1981). Following disturbance, young montane ash trees exhibit rapid rates of growth, and in the case of mountain ash, they may reach $50 \mathrm{~m}$ in height within 35 years of germination (Ashton 1975), and eventually exceed $90 \mathrm{~m}$ after $250+$ years (Ashton 1976). However, the development of hollows in mountain ash trees is a prolonged process, with cavities generally not apparent until trees are at least 120-150 years old (Lindenmayer et al. 1993b). Large hollows are often not found in trees until they are at least 190 years old (Smith and Lindenmayer 1988). Cavity development is generally very slow because it is driven by the activities of termites, fungi, bacteria, and fire; animals such as woodpeckers responsible for accelerating the development of hollows on other continents do not occur in Australia (reviewed by Gibbons and Lindenmayer 2002). Therefore, the greatest abundance of living trees with hollows is typically found in stands of old-growth montane ash, as revealed by statistical analyses of extensive past cross-sectional data sets (Lindenmayer et al. 1991b, 2000). The process of cavity development can sometimes be accelerated when wildfires burn the large trees that characterize old-growth stands. Pulses of large dead and living fire-scarred trees were created by 

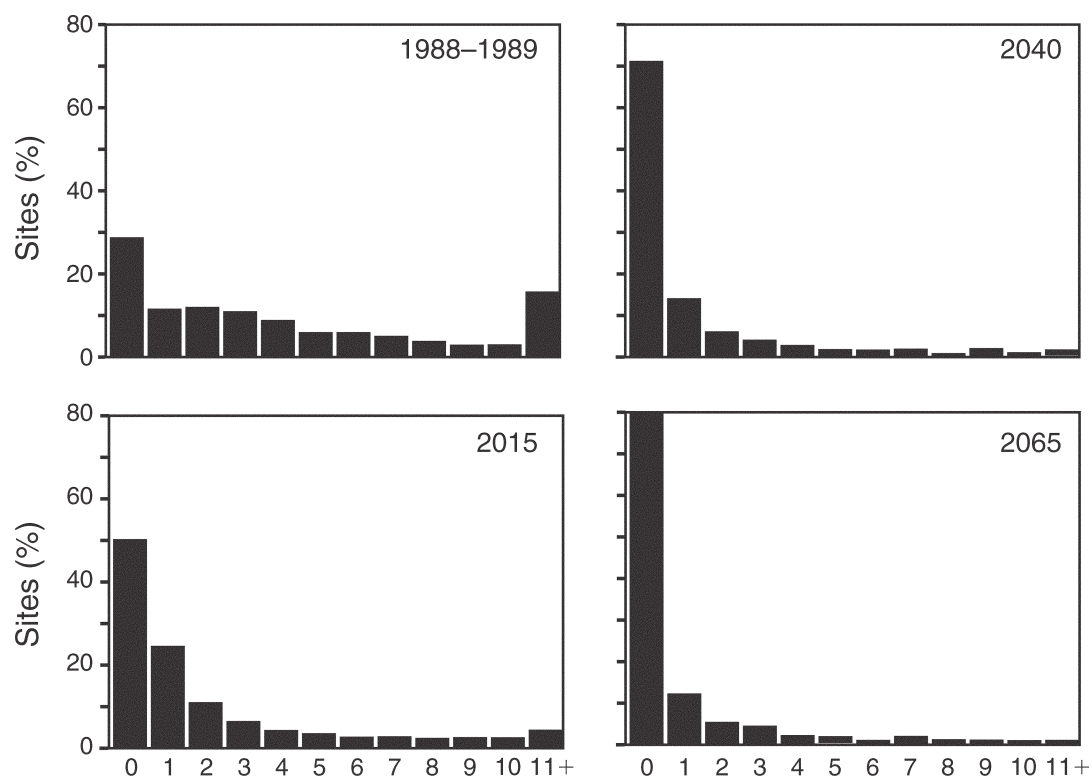

Number of hollow-bearing trees per site

FIG. 1. Projected changes in the abundance of trees with hollows in stands in the montane ash forests of the Central Highlands of Victoria, Australia (redrawn from Lindenmayer et al. [1990a]). The projections are based on measurements of trees at 521 sites, each of 3 ha in size and broadly distributed throughout the montane ash forests of the Central Highlands of Victoria.

extensive wildfires that have occurred in montane ash forests since the mid-1700s, but particularly after conflagrations in 1939 and 1983 (Lindenmayer et al. $1991 b)$. These large trees with hollows may remain standing for many decades after they have been burned, and are therefore biological legacies (sensu Franklin et al. 2000) of past stands.

We previously monitored the condition and numbers of all trees with hollows at an array of long-term field sites located within montane ash forests using repeated surveys (1983-1988-1993) completed during a 10-year period (Lindenmayer et al. 1997). As part of that earlier work, we documented the rate of collapse of trees with hollows and the patterns of decay of these trees (Lindenmayer et al. 1997). We found that $4.4 \%$ of the measured population of trees with hollows collapsed per year between 1983 and 1993, and the rate of collapse was relatively constant (Lindenmayer et al. 1990a, 1997). In addition, we previously found that dead trees in an advanced state of decay were those with the highest probability of collapse (Lindenmayer et al. 1990a, 1997). As part of that earlier work, we made projections of the future availability of trees with hollows until 2065 (Fig. 1 ), because this is the anticipated period needed to elapse until existing regrowth trees that dominate the Central Highlands region will reach an age when they begin to develop cavities suitable for use by arboreal marsupials (Lindenmayer et al. 1993b).

Our hypotheses about relationships between hollowtree abundance and the selection of trees with hollows as nest sites by arboreal marsupials were based on an ongoing static rate of predicted decline in the abundance of trees with hollows that we had observed in earlier investigations. However, a key part of our work was to examine this assumption with a new longitudinal data set on tree condition and collapse that we collected between 1997 and 2006, and which was gathered concurrently with longitudinal data on arboreal marsupials.

\section{Tree hollow-dependent arboreal marsupials in montane ash forests}

Large trees with hollows are the sole nesting and denning sites for virtually all of the eight species of arboreal marsupials that occur in montane ash forests (Lindenmayer et al. 1996b), with some taxa spending $\sim 75 \%$ of their lives within cavities in trees (Smith et al. 1982). These eight species are the nationally endangered Leadbeater's possum (Gymnobelideus leadbeateri), the vulnerable yellow-bellied glider (Petaurus australis), the greater glider (Petauroides volans), the mountain brushtail possum (Trichosurus cunninghami), the sugar glider (Petaurus breviceps), the feathertail glider (Acrobates pygmaeus), eastern pygmy possum (Cercartetus nanus), and the common ringtail possum (Pseudocheirus peregrinus).

The eight species of arboreal marsupials in montane ash forests vary in a range of life history attributes such as body size, group size, mating system, and social organization (Lindenmayer 1997). Past work also has shown that these different species: (1) select different morphological forms of trees with hollows as nest and 


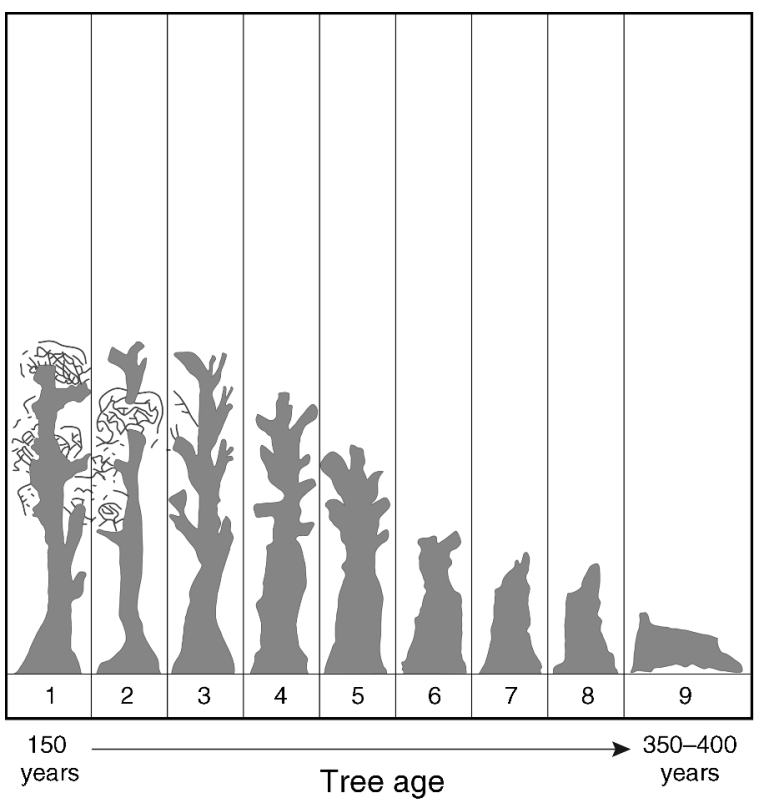

FIG. 2. A diagrammatic representation of relationships between the form classes of trees with hollows in montane ash trees and the occupancy of such trees by different species of arboreal marsupials. Tree form classes span tall, living intact trees with hollows (form 1) through to short, highly decayed trees in the late stages of senescence (form 8): form 1, mature, living tree; form 2, mature living tree with a dead or broken top; form 3, dead tree with most branches still intact; form 4, dead tree with $0-25 \%$ of the top broken off; form 5 , dead tree with top $25-50 \%$ broken away; form 6 , dead tree with top $50-75 \%$ broken away; form 7 , solid dead tree with $\geq 75 \%$ of the top broken away; form 8 , hollow stump; form 9, collapsed tree. Earlier cross-sectional studies revealed that trees in forms 1-3 were those most often used by the sugar glider and greater glider, whereas Leadbeater's possum and the mountain brushtail possum most often occupied trees in forms 6-8.

den sites, ranging from intact, living trees through to highly decayed dead trees in the late stages of senescence (see Fig. 2) (Lindenmayer et al. 1991e), and (2) rarely cooccur in the same tree (Lindenmayer et al. 1990b). Different kinds of trees with hollows in montane ash forests have different insulative properties, as well as different-sized cavities (Lindenmayer et al. 1993b). Such differences may influence interspecific variations in the types of nest trees selected by animals, particularly because differences in tree morphology can affect: (1) the thermal properties of tree cavities and, in turn, influence thermoregulation and energy expenditure, and (2) cavity entrance size, which can be critical for excluding competitors and predators (reviewed by Gibbons and Lindenmayer 2002).

In earlier cross-sectional studies, we identified positive relationships between the abundance of trees with hollows within forest stands and the species richness and abundance of arboreal marsupials in those stands (Lindenmayer et al. 1990c, 1991d) (Fig. 3). The performance of these statistical relationships was examined with a new cross-sectional data set gathered at a new set of 55 field sites in 1993-1994, and they were found to be robust when tested (Lindenmayer et al. 1994). Thus, the availability of trees with hollows was previously hypothesized to be a key factor limiting populations of arboreal marsupials in montane ash forests (Lindenmayer et al. 1991b). Hence, a key assumption was that no arboreal marsupials would occupy sites lacking trees with hollows. We tested and verified this assumption by completing survey work for arboreal marsupials on sites where there were no trees with hollows (Lindenmayer et al. 1991b).

\section{Hypotheses}

Based on the conclusions of earlier cross-sectional studies, we tested the following hypothesis:

Hypothesis 1.-Previously developed statistical relationships between the abundance of hollow trees and the species richness and the abundance of arboreal marsupials would remain unchanged over time despite ongoing losses of trees with hollows. Thus, arboreal marsupials would decline at a rate consistent with losses of trees with hollows.

We tested Hypothesis 1 with longitudinal data on the abundance of arboreal marsupials gathered on a repeated basis between 1997 and 2007 from 160 permanent field survey sites that we established. We included data on other potentially important factors, like annual rainfall, to provide quantification of the effects of background variability and hence assist in the analysis and the interpretation of temporal patterns in animal abundance. To provide an appropriate spatial context for our analyses, we also modeled the effects of other potentially important stand-level attributes such as forest age and forest type.

The test of Hypothesis 1 summarized above was designed to contrast predictions from earlier investigations with the results of the longitudinal study we report here. Deviations from these predictions might indicate processes, such as behavioral adaptations to altered resource availability (Hartwig et al. 2004, Holloway and Malcolm 2007), that were not detectable with a crosssectional approach (Holmes and Sherry 2001, Kruuk and Hill 2008). Thus, we set up a series of alternative hypotheses representing scenarios in which populations of arboreal marsupials did not decline in ways consistent with the availability of hollow-bearing trees and according to previously established relationships. These alternative hypotheses were:

Hypothesis 2.-The decline in the abundance of trees with hollows would disproportionately affect some species at the stand level. Candidate species included Leadbeater's possum and the mountain brushtail possum because past work indicated they selected highly decayed dead trees as nest sites (Lindenmayer et al. 1991e), which also suffer the greatest rates of collapse (Lindenmayer et al. 1997).

Hypothesis 3.-Concentration effects would be observed, whereby the number of animals detected per tree 

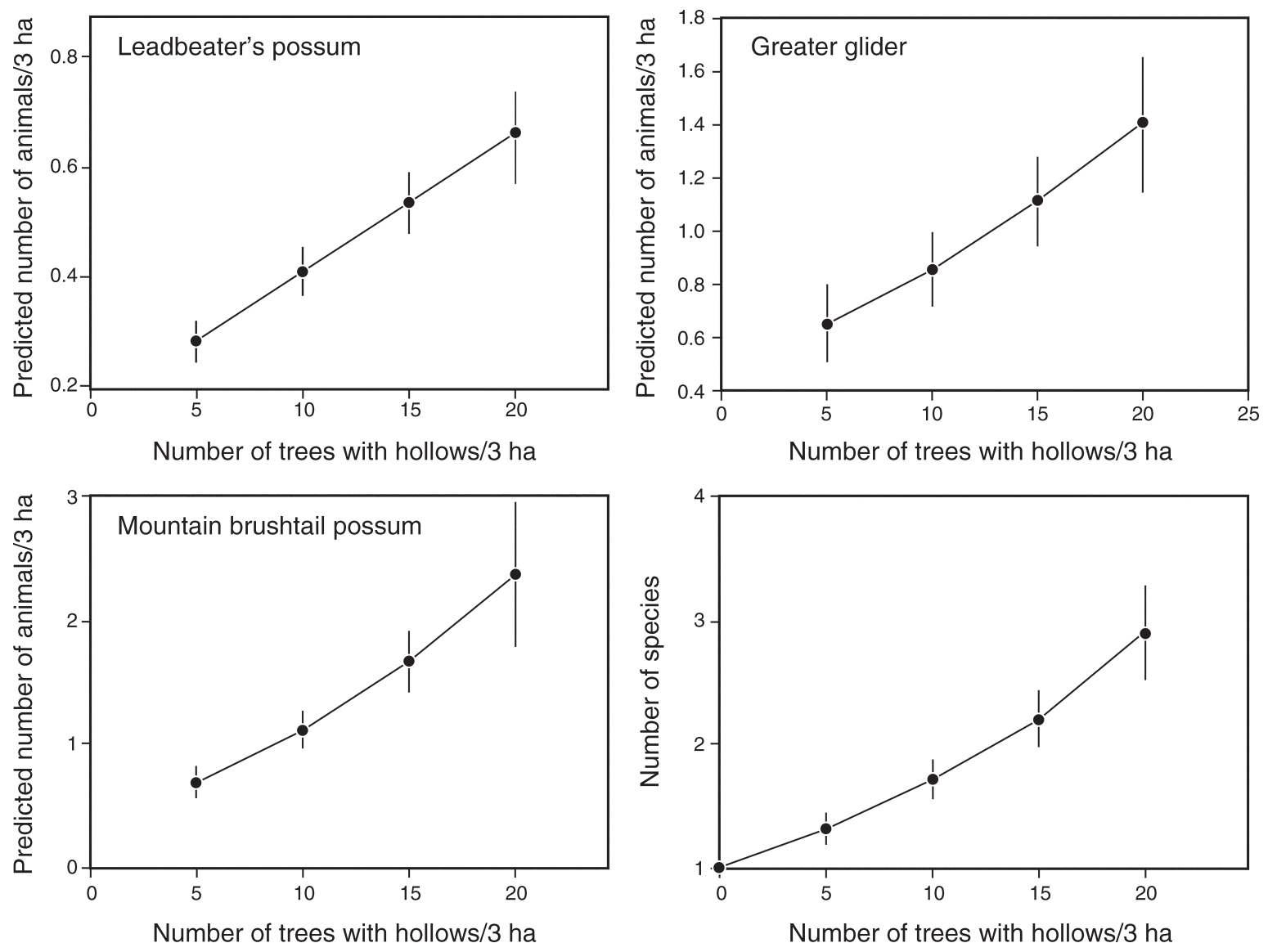

FIG. 3. The relationships between the abundance of trees with hollows in stands and the presence of Leadbeater's possum, the greater glider, the mountain brushtail possum, and species richness (redrawn from Lindenmayer et al. [1990c, 1991d]) developed from past cross-sectional studies. Error bars are \pm SE.

increased above the relationship predicted from the cross-sectional study as hollow-bearing trees are lost. This may be a demographic mechanism of compensating for the loss of tree hollow resources.

Hypothesis 4.-Arboreal marsupials would respond to a decline in the abundance of trees with hollows by being flexible in their tree selection. Previously we developed statistical models of relationships between the morphological characteristics of trees and tree occupancy. For example, we found that the greater glider typically used large living or recently dead trees as nest sites, whereas Leadbeater's possum and the mountain brushtail possum typically occupied dead, highly decayed trees with hollows (Lindenmayer et al. 1991e) (Fig. 2). Notably, these models of nest tree requirements performed well when tested on a second cross-sectional data set gathered from montane ash forests (Lindenmayer et al. 1994). We used a longitudinal data set on the attributes of individual trees with hollows and occupancy patterns of such trees gathered between 1997 and 2007 to test for changes in the relationships quantified in an earlier cross-sectional study in association with the decline of tree hollow resources.

\section{Methods \\ Study area}

Our study focused on the montane ash forests of the Central Highlands of Victoria, southeastern Australia. The Central Highlands region lies about $120 \mathrm{~km}$ northeast of the city of Melbourne and covers approximately one-half degree of latitude and one degree of longitude $\left(37^{\circ} 20^{\prime}-37^{\circ} 55^{\prime} \mathrm{S}\right.$ and $145^{\circ} 30^{\prime}-146^{\circ} 20^{\prime} \mathrm{E}$ ) (Fig. 4). The region experiences mild, humid winters with occasional periods of snow. Summers are generally cool. The area is classified as Cfb under the Köppen system of climatic classification (Dick 1975). A climatic analysis of the study area using the BIOCLIM computer model gave a range of $7.8-13.4^{\circ} \mathrm{C}$ in the mean annual temperature. Mean annual precipitation varied from 975 to $1700 \mathrm{~mm}$. Further information on the study area including climate, land use, and other features are given in Lindenmayer et al. (1996a).

\section{Field monitoring sites}

In 1997 we established 160 permanent monitoring sites, each measuring 1 ha in size throughout the 

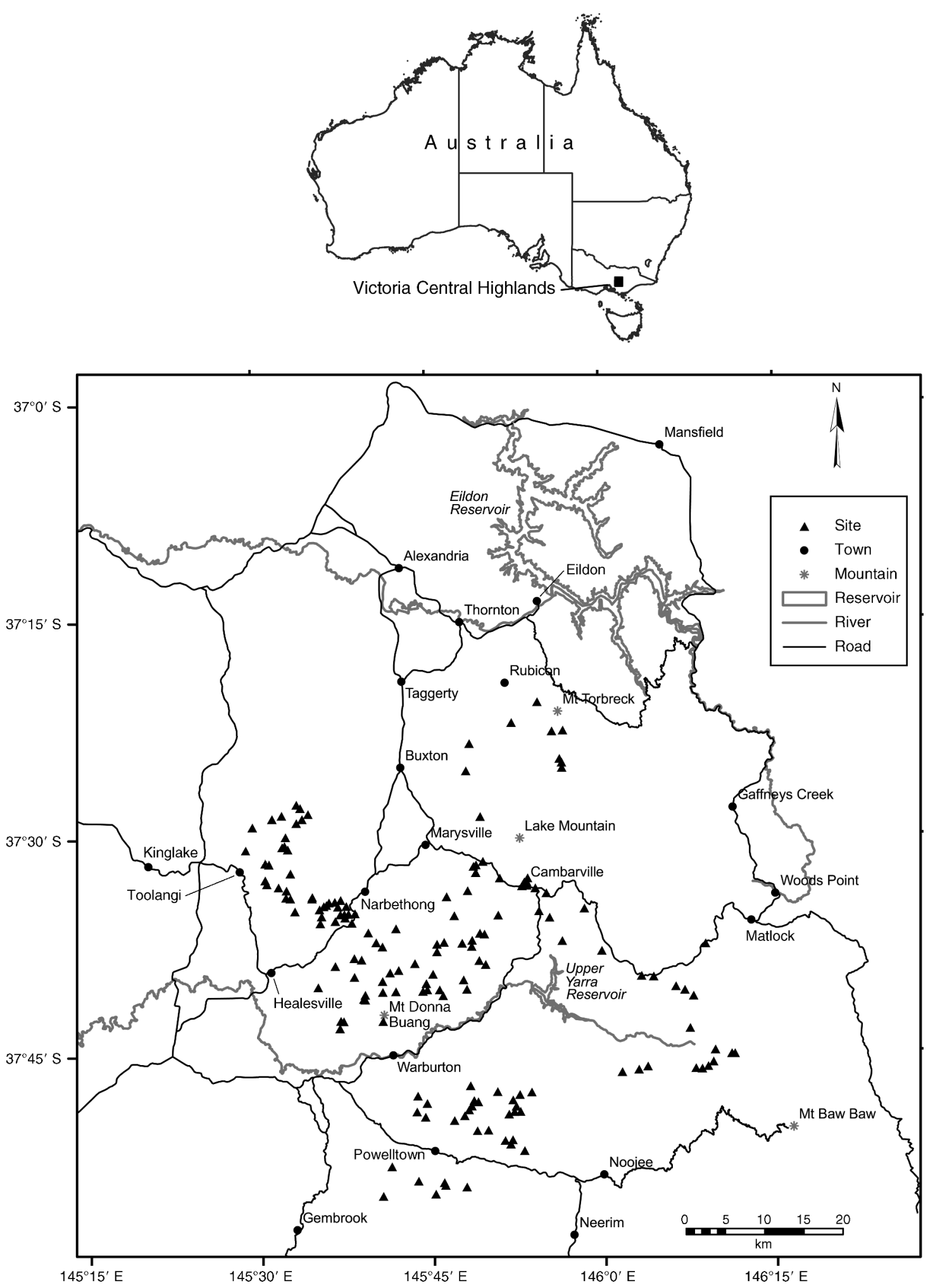

FIG. 4. The broad location of the study region in the Central Highlands of Victoria, southeastern Australia. 
montane ash forests of the Central Highlands of Victoria (Lindenmayer et al. 2003). These included 140 sites established in earlier studies dating back to 1983 , 1988, and 1992. Sites were well distributed throughout the study region. We located a total of 81 sites in areas broadly designated for timber harvesting operations, although none were logged between 1985 and 2007. The remaining 79 of our sites were in closed water catchments and the Yarra Ranges National Park, where logging is excluded. This distribution of sites enabled us to make cross-tenure comparisons of temporal patterns of tree fall and animal abundance.

Our 160 field sites covered a wide range of variation in environmental conditions. The number of trees with hollows on a site ranged from 1 to 31 . Our sites varied in dominant tree species (mountain ash, alpine ash, shining gum), slope angle (inclination: $2-38^{\circ}$ ), aspect, elevation $(220-1040 \mathrm{~m})$ and topographic position (gully, midslope, ridge). We recognized several forest age groupings including those dating from the mid-1700s, mid-1850s, the early 1900s $(1905,1919,1926$, and 1932), 1939, and 1983. We ensured that there was a minimum of eight sites in each forest age cohort, but we examined more stands in 1939-aged forest than other age cohorts (Lindenmayer et al. 2003). This was because forests dating from the extensive 1939 conflagration dominate the Central Highlands of Victoria and comprise $>70 \%$ of the ash-type eucalypt forest in the region.

Longitudinal data collection: measurements of the condition and collapse of large trees with hollows

At the commencement of our study in 1997, we mapped and permanently marked all trees with hollows on each of the 160 field sites. We defined a tree with hollows as any tree $>0.5 \mathrm{~m}$ in diameter containing one or more obvious cavities (as determined from repeated ground-based observations using binoculars). We assigned each tree to one of eight tree form or decay classes based on readily observable external characteristics (see Fig. 2). These were: form 1, mature, living tree; form 2, mature living trees with a dead or broken top; form 3, dead tree with most branches still intact; form 4, dead tree with $0-25 \%$ of the top broken off; branches remaining as stubs only; form 5, dead tree with top 25 $50 \%$ broken away; form 6 , dead tree with top $50-75 \%$ broken away; form 7 , solid dead tree with $\geq 75 \%$ of the top broken away; form 8 , hollow stump. In subsequent surveys we added a ninth category: form 9, collapsed tree. Thus, our population of marked trees encompassed both living and dead stems with hollows, the reason why we did not use the term "snag" commonly employed in North America (e.g., Cline et al. 1980).

We assessed all trees with hollows on each site in two ways. First, each time we visited a site to complete nighttime (stagwatch) monitoring of arboreal marsupials (see the following section), we recorded whether a given marked and numbered tree was still standing and its current form or if it had collapsed to the ground (making it no longer suitable as a den or nest tree for an arboreal marsupial). Second, we undertook a complete re-survey of the form of all trees with hollows on all 160 monitoring sites in late 2006, $\sim 10$ years after we commenced this study.

Because montane ash trees exceed 120 years before they begin to develop cavities (Ambrose 1982) and the vast majority of stands we studied were dominated by regrowth trees (Lindenmayer et al. 1993b), we assumed there was no recruitment of new hollow trees between the time we instigated our investigation and the subsequent periods when we remeasured trees on each site. To confirm this, each time we re-surveyed our field sites, we completed an additional reconnaissance in which all overstory eucalypt trees on each site were carefully inspected with binoculars. This was done to determine if any new trees with hollows had been recruited since the previous survey. No additional trees were found on our field sites during the 10 years of this study.

\section{Longitudinal data collection: counts of arboreal marsupials}

We counted populations of arboreal marsupials on our 160 field sites using the stagwatching method (sensu Seebeck et al. 1983, Lindenmayer et al. 1991a). This method involves counting the number of individuals of each species of arboreal marsupial emerging from each marked tree with a hollow on each surveyed field site (Lindenmayer et al. 1991a). Stagwatching has been developed specifically for studies of arboreal marsupials in the wet forests of Victoria (Seebeck et al. 1983). Notably, the stagwatching technique is the most reliable method for obtaining a count of the number of arboreal marsupials at a site. This is because the density of the luxuriant understory and ground layers in montane ash forests makes other methods like spotlighting highly problematic; observers cannot move easily and quietly through the vegetation and animals cannot be readily detected in a light beam (Smith et al. 1989, Lindenmayer 2009). In addition, in our stagwatching surveys, all trees with hollows on a given site are observed simultaneously by multiple, trained observers. We followed this procedure because radiotracking studies have demonstrated that individual animals move regularly between different trees with hollows on a given site (Lindenmayer and Meggs 1996, Lindenmayer et al. 1996b). We commenced each stagwatching survey an hour before dusk and continued it until an hour after dusk to ensure that both small-bodied species and large-bodied species were detected. This was because previous work indicated there is a highly significant relationship between the body size of different species of arboreal marsupials and time of emergence from a tree with hollows (Lindenmayer et al. 1991c). Small-bodied species emerge before or around dusk, whereas large-bodied species typically emerge up to 30-40 minutes after dusk (Lindenmayer et al. 1991c). We employed the same stagwatching 
TABLE 1. Number of sites surveyed by stagwatching for arboreal marsupials in each year in the study region in the montane ash eucalypt forests of Central Highlands of Victoria, southeastern Australia.

\begin{tabular}{ccc}
\hline \hline Year & Number of sites & $\begin{array}{c}\text { Number of sites } \\
\text { from previous year }\end{array}$ \\
\hline $1997 / 1998$ & 76 & \\
$1998 / 1999$ & 84 & \\
$1999 / 2000$ & 51 & 21 \\
$2000 / 2001$ & 52 & 25 \\
$2001 / 2002$ & 55 & 42 \\
$2002 / 2003$ & 38 & 30 \\
$2003 / 2004$ & 44 & 29 \\
$2006 / 2007$ & 21 & 17 \\
$2007 / 2008$ & 28 & 18 \\
\hline
\end{tabular}

Note: Stagwatching is a nighttime count of the number of individuals of each species of arboreal marsupial emerging from each marked tree with a hollow on each surveyed field site. See Methods: Longitudinal data collection: counts of arboreal marsupials.

protocols throughout the entire 10 years of this investigation to ensure that the integrity of our data set was not breached, a key consideration in robust longitudinal studies (see Strayer et al. 1986). We have repeatedly explored detectability issues associated with the stagwatching method for a range of different species of arboreal marsupials, both in the Central Highlands of Victoria and elsewhere in southeastern Australia. We have done this using radio-collared animals that have been tracked to their daytime nest sites within large trees with hollows. Trained observers then complete a stagwatch survey on a field site supporting collared animals, but the locations of occupied trees are not revealed to them. This procedure for examining the detectability of different species of arboreal marsupials and thereby testing the effectiveness of the stagwatching method has been completed repeatedly as part of studies on a range of taxa including: (1) Leadbeater's possum (Lindenmayer and Meggs 1996); (2) mountain brushtail possum (Lindenmayer et al. 1996b; see Plate 1); (3) greater glider (Pope 2003); (4) squirrel glider (Petaurus norfolcensis) (a similar species to the sugar glider, although larger) that occurs in woodland environments in southern New South Wales (Crane et al. 2008); and (5) the common ringtail possum within coastal forests and shrublands in New South Wales (Lindenmayer et al. 2008). The results of such work have been consistent whenever and wherever we have completed it; observers always detect collared animals emerging from trees with hollows $(n=$ 224). The conclusion from this combined set of studies of arboreal marsupials is that problems with animal detection are most unlikely to have had a major effect on our data sets.

Our survey program for arboreal marsupials used an overlapping and rotating sampling protocol (Welsh et al. 2000) in which surveyed sites were selected from our population of 160 monitoring sites. In the initial two years of our study (1997-1998), all 160 sites were surveyed. In each subsequent year, we selected a subset of $\sim 30-60$ of the 160 sites for survey (see Table 1). We based the probability of site selection on the count of the number of animals recorded on those sites in the previous surveys, including the census years of 19971998. However, we note that in any given year, there were many sites in the selected pool of sites that supported few trees with hollows (and therefore were likely to support relatively few animals). Overall, our monitoring design allowed for $\sim 60 \%$ of all sampled sites to remain the same in consecutive years (Lindenmayer et al. 2003). However, logistical considerations led to some slight departures from this scheme in the field. The statistical advantages of nonstandard overlapping and rotating sampling approaches in monitoring programs are discussed in detail by Welsh et al. (2000).

\section{Statistical AnAlysis}

Our statistical analyses were aimed at addressing Hypotheses 1-4. Hypothesis 1 was concerned with comparing predictions from the earlier cross-sectional studies with data from the present longitudinal study. Hypotheses 2-4 tested for biological responses to hollow-tree loss that led to deviations from the predictions of previous cross-sectional research.

\section{Temporal changes in the decay and collapse of trees with hollows}

We modeled the collapse of trees with hollows using generalized linear modeling (McCullagh and Nelder 1989) with a complementary log-log link. We selected this link because the parameters of the models can be directly interpreted in terms of their effect on the rate of tree decay. If we assume a constant rate of decay, $\lambda$, if necessary after some appropriate transformation of time, the chance that a tree with hollows is still standing after time $t$ will be $\exp (-\lambda t)$. The probability of collapse is $P_{\mathrm{c}}=1-\exp (-\lambda t)$. Hence, $\log \left(-\log \left(1-P_{\mathrm{c}}\right)\right)=\log (\lambda)+$ $\log (t)$, and the parameters of such a generalized linear model can be used to estimate the rate of decay, $\lambda$. We used similar models to investigate the transitions of trees in a given state of decay to other decay classes or forms.

We estimated the rates of transition between different forms by calculating the fraction of trees in a decay class that had either stayed in the same class, or that had decayed to each of the more decayed classes between 1997 and late 2006. We describe these transitions for trees in different groups of forms (decay classes 1-2, 3-5, 6,7 , and 8). We then used these transition probabilities to calculate the estimated future distribution of decay classes at eight-year intervals by repeatedly multiplying the current vector of numbers in the different groups by the estimated transition matrix, and in particular in 2054, the approximate time when research on cavity development by other workers (Ambrose 1982) suggests that trees with hollows in existing stands of 1939 regrowth forest (the most prevalent age class in the study region) will first begin to be recruited and hence added to remaining trees with hollows projected to be 
still standing 40 years from now. These analyses enabled us to determine if the rate of decline in the abundance of trees with hollows and relationships between tree decay state and the probability of collapse were similar to relationships quantified in earlier investigations.

Temporal changes in arboreal marsupial species richness and abundance in relation to decline of trees with hollows

Stand-level analyses.-To address Hypothesis 1 (arboreal marsupials will decline at a rate consistent with the rate of hollow-tree loss according to previously established relationships) and Hypothesis 2 (the decline in the abundance of trees with hollows will disproportionately affect some species), we analyzed patterns of species richness and abundance of arboreal marsupials at the stand (1-ha site) level. We used generalized linear mixed models (GLMMs) (McCulloch and Searle 2001) and hierarchical generalized linear models (HGLMs) (Lee et al. 2006), especially quasi-Poisson models with a logarithmic link, to relate the total numbers of arboreal animals observed at sites to the year and to the number of trees with hollows on those sites. We also fitted binomial models with a logistic link to the presence/ absence of a species at a site.

We included other key variables that might influence species richness and animal abundance. These included stand age and dominant tree species (namely, mountain ash, alpine ash, or shining gum). In addition, we included data on annual rainfall in our analyses to ensure that we could separate annual climate-related fluctuations in populations from longer-term changes like the potential effects of temporal changes in the abundance of trees with hollows. Using monthly rainfall data from the town of Marysville (Australian Government Bureau of Meteorology site 088044) which is located in the center of our study region, we calculated the rainfall in both spring and winter prior to each survey, and also the rainfall in the winter and spring prior to these. We used the logarithm of the number of trees with hollows as a predictor, so that a coefficient of 1.0 would correspond to the animal number at a site being proportional to the number of trees with hollows. We compared the coefficient of this predictor with the values given in Lindenmayer et al. (1993a).

We initially fitted GLMs with all possible combinations of predictors and for each response variable and then selected the model that minimized the Bayesian Information Criterion (BIC, Schwarz 1978). We then refitted this model allowing for random site-to-site variation, and discarded terms that were not significant at the $5 \%$ level in a Wald test.

Tree-level analyses.-To address Hypothesis 3 (concentration effects) and Hypothesis 4 (flexibility of tree selection), we analyzed temporal changes in the presence and abundance of arboreal marsupials at the tree (within-site) level. We used observations of arboreal marsupials emerging from trees with hollows to test relationships between the characteristics of individual trees and occupancy. For occupancy of trees with hollows by individual animal species, we fitted binomial GLMMs with a logit link to presence/absence data from individual trees. Our models at the tree level took account of the systematic effects of tree form as well as random tree to tree variation. We completed analyses of tree form effects to determine if there had been temporal changes in the kinds of trees with hollows occupied by arboreal marsupials.

We selected models for each response variable at the tree level in a similar way to that used in the stand level analyses.

\section{RESUlTS \\ Temporal changes in the decay and collapse of trees with hollows}

We recorded considerable between-site variation in the percentage of trees with hollows that collapsed; it ranged from $0 \%$ on 60 of our 160 sites to $>40 \%$ on 20 of our sites. We found that our underlying assumption of a static long-term rate of tree collapse was not supported by our new longitudinal data set, because the rate had substantially slowed compared to previous studies. Of 1112 large trees with hollows that we measured and marked at the outset of this study in 1997,151 or $13.6 \%$ had collapsed by late 2006. This equated to a mean annual loss of $1.8 \%$ of the total measured population of trees, which was markedly lower than the mean annual loss of $4.4 \%$ that we documented in earlier studies between 1983 and 1993 (see Lindenmayer et al. 1997). This is consistent with the results of Lindenmayer and Wood (2010), who found that for a different group of sites that had been observed over the period 1983-2007, the rate of collapse in 1993-2007 was estimated to be 0.55 (95\% confidence interval $0.39-0.78)$ of the rate of collapse in 1983-1993.

Our data contained evidence that a higher proportion of trees with hollows in the most deteriorated states (forms 6, 7, 8; see Fig. 2) collapsed than less decayed trees, particularly living trees with hollows (forms 1 and 2) (Table 2, Fig. 5). However, the transition process between tree death and collapse (especially for trees in forms 6-8) was not as rapid in the 1997-2007 measurement period as it was in the earlier (19831993) measurement period (Table 2). In addition, the rate of collapse of dead trees in the later forms (6-8) was slower than in earlier studies. Thus, we found only partial support for the underlying assumption that the previously quantified relationship between tree decay state and the probability of collapse would remain unchanged.

\section{Temporal changes in animal numbers}

We recorded individuals of all eight species of arboreal marsupials known to occur in montane ash forests. We present fitted annual mean counts (and associated confidence intervals) in Fig. 8. For Leadbeater's possum and the yellow-bellied glider, these means 
TABLE 2. The numbers of transitions of trees with hollows to a more decayed state between 1997 and 2006

\begin{tabular}{lcccccc}
\hline \hline \multirow{2}{*}{$\begin{array}{c}\text { Initial tree } \\
\text { form in } 1997\end{array}$} & 1,2 & $3,4,5$ & 6 & 7 & 8 & 9 \\
\cline { 2 - 6 } & $240(\mathbf{9 5 . 6 )}$ & $4(1.6)$ & $2(0.8)$ & $1(0.4)$ & $1(0.4)$ & $3(1.2)$ \\
1,2 & $312 \mathbf{( 8 6 . 2 )}$ & $3(0.8)$ & $1(0.3)$ & $1(0.3)$ & $45(12.4)$ \\
$3,4,5$ & & & $154(\mathbf{7 7 . 0 )}$ & $7(3.5)$ & $6(3.0)$ & $33(16.5)$ \\
6 & & & $178(\mathbf{7 2 . 0})$ & $14(5.7)$ & $55(22.3)$ \\
7 & & & & $37(\mathbf{7 1 . 2})$ & $15(28.8)$ \\
8 & & & & & \\
\hline
\end{tabular}

Notes: The percentage of trees changing between decay classes is shown in parentheses. Percentage values in boldface type correspond to categories where no change in tree form occurred during the study period. For descriptions of the tree forms, see Methods: Longitudinal data collection: measurements of the condition and collapse of large trees with hollows.

were adjusted for forest age, which is an important determinant of their presence. Raw counts for individual animals are presented in the Appendix: Table A1.

We found that the mountain brushtail possum, the greater glider, and Leadbeater's possum were relatively common, and the sugar glider and yellow-bellied glider were uncommon. We classified the remaining three species (the common ringtail possum, the eastern pygmy possum, and the feathertail glider) as rare on our study sites (Appendix: Table A1) and excluded them from most of our subsequent statistical analyses.

Stand-level analyses.-We present BIC values for the best 20 candidate models for the response variables considered (Tables A2-A8 in the Appendix). In the case of the rarer species such as the yellow-bellied glider and sugar glider, as well as for species richness, we selected simpler models after allowing for the effect of site-to-site variation. In the case of the other responses, all terms remained significant at the $5 \%$ level after allowing for site-to-site variation.

We found partial support for Hypothesis 1: that the relationships between the abundance of trees with hollows and the species richness and abundance of arboreal marsupials would remain unchanged over time, irrespective of the ongoing loss of trees with hollows. We found that the total number of arboreal marsupials observed at a site was significantly higher on sites with more trees with hollows (Table 3). We also identified a significant positive relationship between the numbers of trees with hollows on a site and the abundance of the two most common species, the greater glider and the mountain brushtail possum (Table 3). However, in contrast to previous work (Lindenmayer et al. 1991b), we found no significant relationship between the abundance of Leadbeater's possum and the abundance of trees with hollows (Table 3), or between species

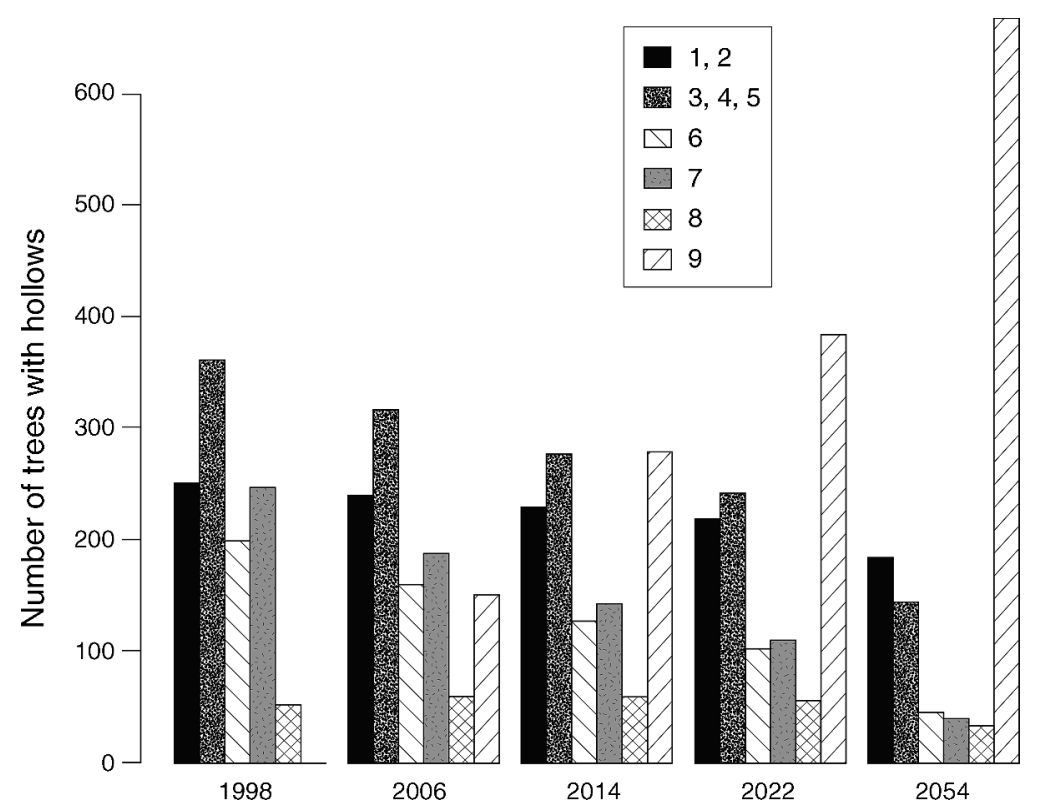

FIG. 5. Actual (field-measured) distribution of tree forms in 1998 and 2006, and the projected distribution of tree forms in 2014 , 2022, and 2054 over 521 3-ha sites. 
TABLE 3. Significant predictors of the abundance of different species of arboreal marsupials on a site based on fitting a hierarchical generalized linear model.

\begin{tabular}{llr}
\hline \hline \multicolumn{1}{c}{ Response variable } & \multicolumn{1}{c}{ Significant predictors } & \multicolumn{1}{c}{$P$} \\
\hline Leadbeater's possum & age category & $<0.001$ \\
Greater glider & logarithm of number of trees with hollows & $<0.001$ \\
& rainfall two winters previously & $<0.001$ \\
Yellow-bellied glider & age category & $<0.001$ \\
& forest type & $<0.001$ \\
& logarithm of number of trees with hollows & 0.032 \\
Sugar glider & forest type & 0.003 \\
& tenure & $<0.001$ \\
Mountain brushtail possum & rainfall previous winter & 0.021 \\
& linear time trend & 0.006 \\
All arboreal marsupials & tenure & 0.041 \\
& logarithm of number of trees with hollows & $<0.001$ \\
Species richness & rainfall previous winter & 0.001 \\
& logarithm of number of trees with hollows & $<0.001$ \\
\hline
\end{tabular}

Note: Significance levels from omitting terms in the maximal model are given in Appendix A: Table A9.

richness and the abundance of trees with hollows per site.

We compared coefficients for statistical relationships between the logarithm of the number of trees with hollows at a site and animal presence, abundance, and species richness based on past cross-sectional work (summarized in Lindenmayer et al. 1993a) with the estimates obtained for similar relationships in this study using our longitudinal data set (Figs. 6 and 7). In many cases, the coefficients for these relationships were smaller now than in previous work, but these differences were not statistically significant. The only significant

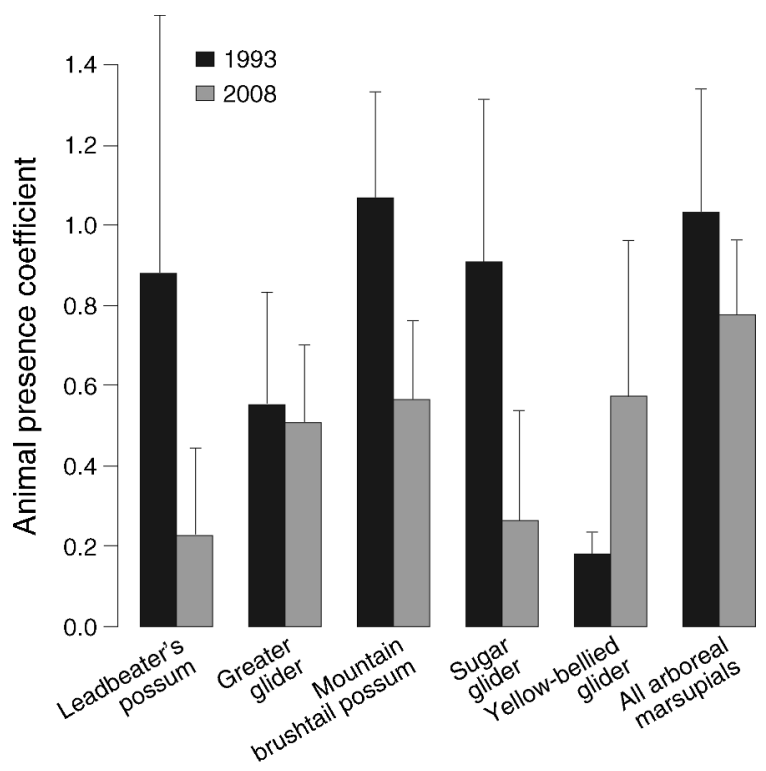

FIG. 6. Coefficients and standard errors from logistic regression of animal presence/absence on the logarithm of the number of trees with hollows based on past cross-sectional work (summarized in Lindenmayer et al. [1993a]) and estimates obtained from longitudinal data gathered between 1997 and 2008. difference we identified between previous and current coefficients was for species richness (at the 5\% level).

We identified stand-level factors in addition to the abundance of trees with hollows that had a significant effect on the abundance of individual species of arboreal marsupials. Leadbeater's possum was significantly more likely to occur in young forest (regenerating after the 1983 fire) than old forest, whereas the yellow-bellied glider was more likely to occur in old forest as well as in

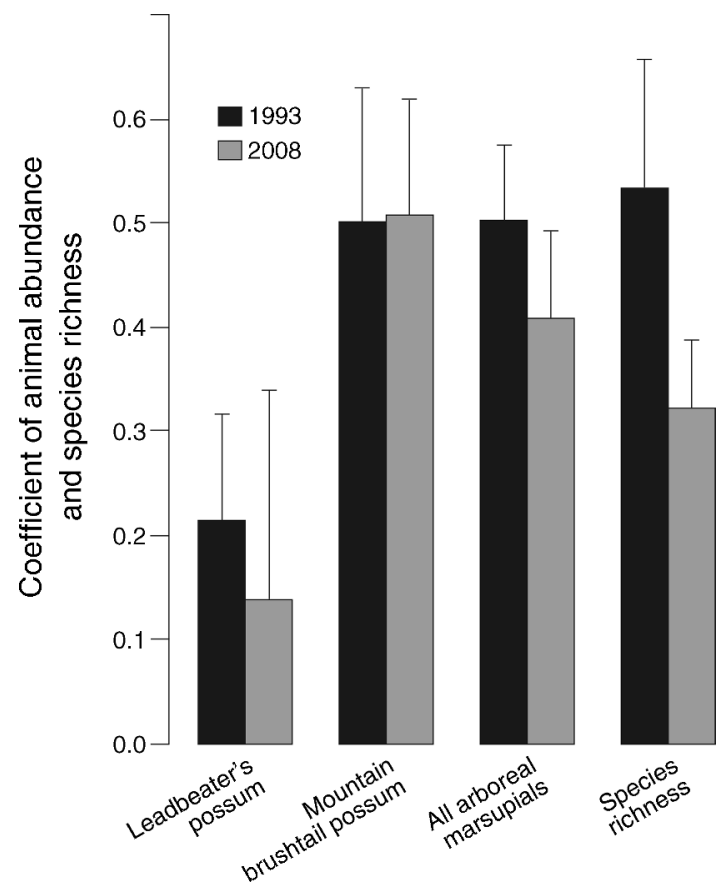

FIG. 7. Coefficients and standard errors from log-linear regression of animal abundance and species richness on the logarithm of the number of trees with hollows based on past cross-sectional work (summarized in Lindenmayer et al. [1993a]) and estimates obtained from longitudinal data gathered between 1997 and 2008. 

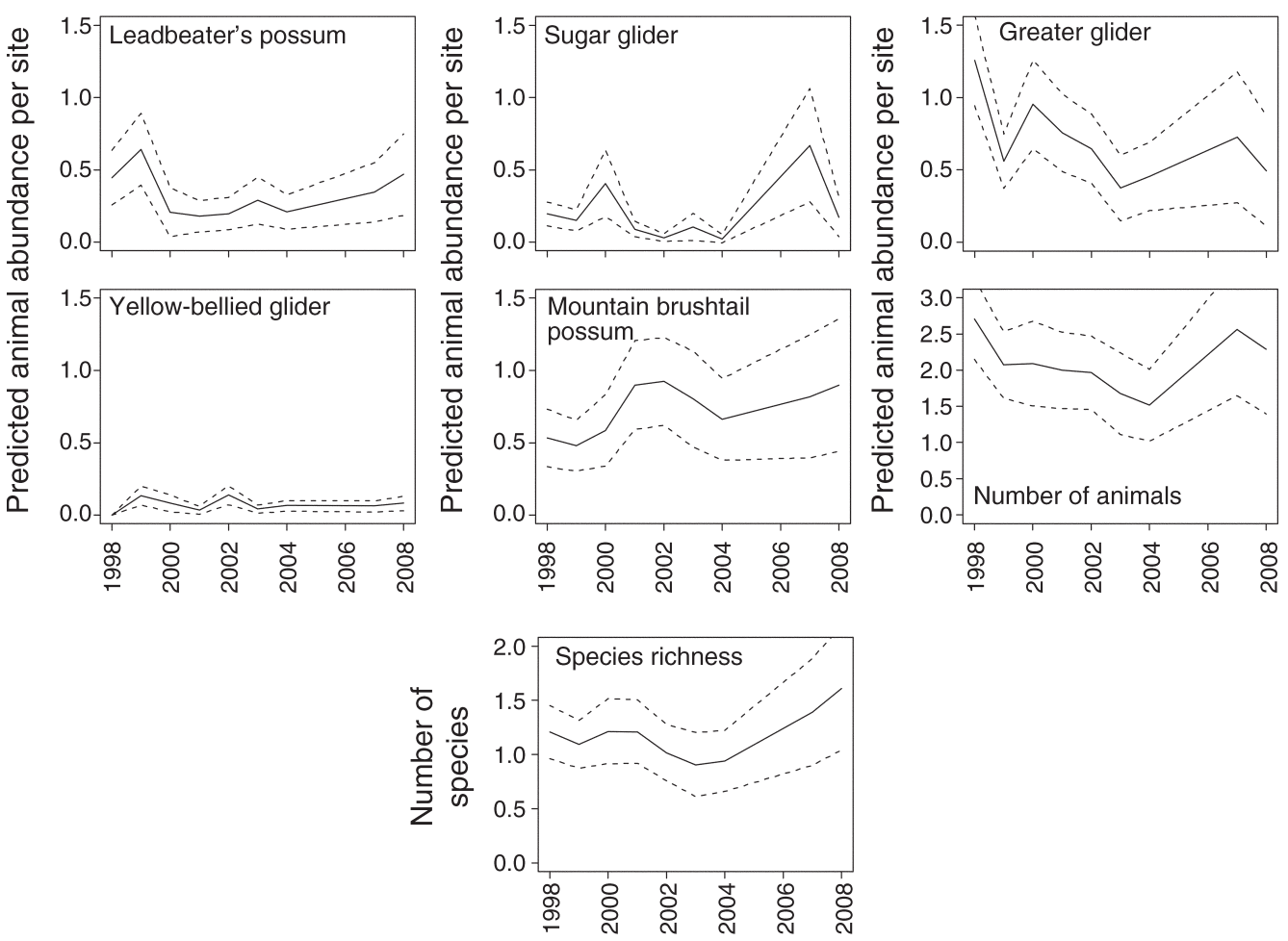

FIG. 8. Predicted animal abundance per site with 95\% confidence intervals (dashed lines) for each year (1998-2009) for five species of arboreal marsupials, for total abundance, and for species richness (which includes all eight species surveyed). The values we present account for interannual differences in the number of sites that were stagwatched (see Appendix A: Table A1).

stands of shining gum rather than the other forest types (i.e., mountain ash or alpine ash) (Table 3). The sugar glider also was more likely to occur in old forest and on sites located in the Yarra Ranges National Park (Table 3 ). The mountain brushtail possum also was more likely to occur on sites within the Yarra Ranges National Park (Table 3).

To address Hypothesis 2 (that some species would be disproportionately affected at the stand level by the loss of trees with hollows), we also completed an assessment of the temporal variation in animal abundance. The estimated annual average numbers of each of the common and uncommon species per site (and associated 95\% confidence intervals) are shown in Fig. 8. Ignoring random year-to-year variation, we found that the greater glider (Fig. 8e) declined significantly during the 10 years of our study, but there were no other discernible trend patterns for increasing or decreasing abundance in the other species. The estimated annual rate of decline of the greater glider was $8.8 \%$ per year with a $95 \%$ confidence interval $(2.2-15.8 \%)$. This temporal trend could be largely explained by rainfall, with a significant negative relationship between the abundance of the species in a given year and rainfall two winters previously (Table 3). We also found that the total number of animals observed at a site in a given year was significantly lower when the amount of rainfall in the previous winter was low. We identified a similar effect of rainfall in the previous winter on the abundance of the sugar glider. No rainfall relationships were identified for other species of arboreal marsupials (Table 3).

We found no evidence that particular taxa like uncommon or rare species were those most likely to be lost from sites with a decline in, and hence a reduced abundance of, trees with hollows. Moreover, we found no apparent negative relationship between the occurrence of uncommon or rare species and the occurrence of the two most common species (the mountain brushtail possum and the greater glider). Of 163 field surveys in which neither of these two common species occurred, at least one of the uncommon or rarer species (the yellow-bellied glider, the eastern pygmy possum, the feathertail glider, and the common ringtail possum) occurred in $10 \%$ of surveys, compared with $8 \%$ of the 276 surveys when at least one of the two common species was observed. Thus, we found no systematic evidence to support Hypothesis 4 that common species competitively dominated sites with few trees with hollows.

Tree-level analyses.-We completed 4319 observations of individual trees for the emergence of arboreal marsupials. A surprising finding from our longitudinal data set was support for Hypothesis 3 (concentration effects), whereby the number of animals detected per tree decreased as the stand-level abundance of trees with hollows increased (Table 4, Fig. 9). The probability of seeing any arboreal marsupial in a tree (irrespective of 
TABLE 4. Significant predictors of the probability of observing an animal emerging from an individual tree with hollows based on fitting a hierarchical generalized linear model.

\begin{tabular}{llr}
\hline \hline \multicolumn{1}{c}{ Response variable } & \multicolumn{1}{c}{ Significant predictors } & \multicolumn{1}{c}{$P$} \\
\hline Leadbeater's possum & age category & $<0.001$ \\
& logarithm of number of trees with hollows & $<0.001$ \\
Greater glider & rainfall two winters previously & 0.005 \\
& tree form & $<0.001$ \\
& tenure & 0.005 \\
Mountain brushtail possum & logarithm of number of trees with hollows & $<0.001$ \\
Any arboreal marsupial & logarithm of number of trees with hollows & $<0.001$ \\
\hline Note: Significance levels from omitting terms in the maximal model are given in Appendix A:
\end{tabular}
Table A10.

species) was significantly negatively related to the number of trees with hollows on a site (Table 4). This relationship was highly significant for Leadbeater's possum (Table 4) with the estimated probability of seeing at least one individual emerging from a tree with hollows being 0.05 for a site with one tree with a hollow and 0.02 for a site with 10 trees with hollows. Similarly, the probability of observing a mountain brushtail possum or greater glider in a tree was significantly negatively related to the number of trees with hollows on a site (Table 4).

With the exception of the greater glider, no additional variables were significant in any of the tree-level models we developed. We found that the probability of seeing the greater glider emerging from a tree was significantly affected by two factors in addition to tree form and the abundance of trees with hollows. These were: (1) tenure; the probability of observing the species was significantly higher on our sites located in the Yarra Ranges National Park, and (2) year; the probability of detection was significantly higher in 1997-1998 and 1999-2000 than in later years (Table 4).

Our tree-level analyses of relationships between tree form and animal occupancy (Hypothesis 4) produced dissimilar findings to those obtained in earlier work for two species, the mountain brushtail possum and Leadbeater's possum. Unlike previous cross-sectional work, we did not identify tree form relationships for either Leadbeater's possum or the mountain brushtail possum. However, consistent with previous findings, the greater glider selected tall, relatively intact living or recently dead trees with hollows (see Fig. 2). As in earlier work, the probability of detecting a greater glider decreased significantly with increasing levels of tree decay (Table 4). We also found in this study that the probability of seeing any arboreal marsupial in a tree (irrespective of species) was significantly lower in trees in the more advanced stages of decay (forms 6-8) (Table 4).

\section{Discussion}

We posed two broad questions in the Introduction to this paper: (1) Do predictions based on cross-sectional studies hold when tested with longitudinal data? And (2)
What additional insights can be gained through longitudinal research? We used the results of our earlier studies, including a set of major cross-sectional investigations, to construct questions and hypotheses about changes in relationships between habitat resources and animal abundance, which we subsequently tested with longitudinal data. To do this, we have undertaken a set of large-scale, long-term investigations that have encompassed many sites surveyed repeatedly over time. We have targeted a known critical structural feature of forests, large trees with hollows, and carefully monitored animal species closely associated with this resource.

\section{Do predictions based on cross-sectional studies hold when tested with longitudinal data?}

The key predictions based on earlier cross-sectional studies that we tested in this study were associated with relationships between the abundance of trees with hollows and animal abundance and nest tree selection. We found that some of our a priori predictions held, whereas others partially held. For example, we found that most current relationships between the abundance of trees with hollows and the abundance of animals at the site level were not significantly different from equivalent relationships developed from earlier crosssectional work. Thus, Hypothesis 1 was not fully rejected, although for such species as Leadbeater's possum, we identified different tree abundance-animal abundance relationships to those found previously. In addition, for all species of arboreal marsupials except the greater glider, we detected no statistically significant temporal decline. This finding was the basis of additional research, which as we discuss in the following section, was possible only through the collection of longitudinal data.

At the tree level, we found that Hypothesis 4 concerning altered nest tree selection held for some species when tested with longitudinal data. In addition, the probability of recording any individual species of arboreal marsupial, and an arboreal marsupial per se (irrespective of species) in a tree, was greatest on sites with few trees with hollows. This relationship was not apparent in earlier cross-sectional analyses of tree occupancy (Lindenmayer et al. 1990b), indicating the 

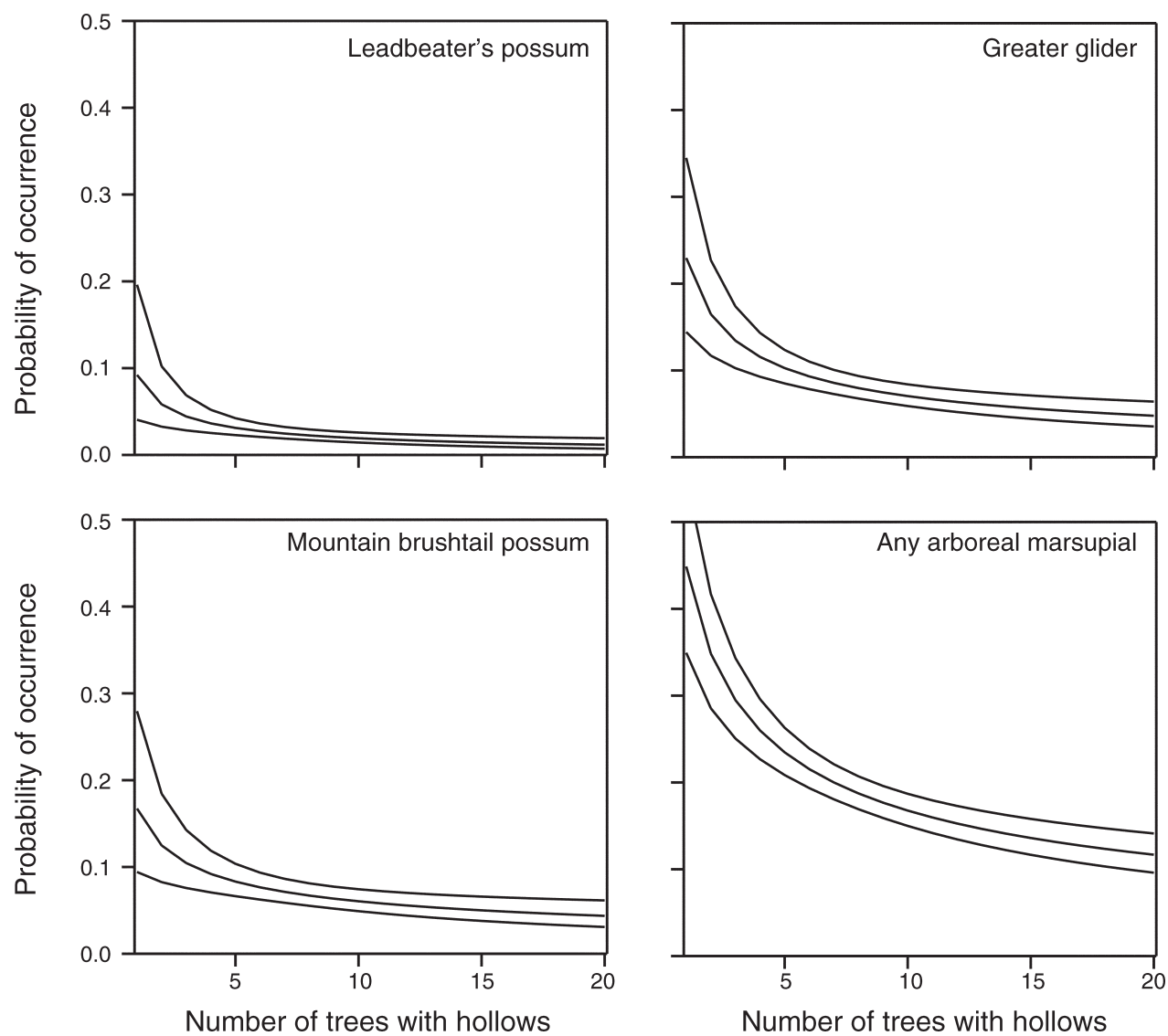

FIG. 9. Probability of occurrence of an animal in a tree with hollows as a function of the number of trees with hollows at a 1-ha site.

existence of concentration effects, consistent with our Hypothesis 3. Together, these findings suggest that the habitat requirements of individual species may change, sometimes considerably, over time. Habitat suitability for individual species is often considered as a static construct (e.g., Hall et al. 1997), but several studies (e.g., Haila et al. 1996) have reported how it can change on a temporal basis, again demonstrating the value of longitudinal studies, as we discuss below.

\section{What additional insights can be gained through longitudinal research?}

Longitudinal studies can lead to new insights and surprises not provided by cross-sectional data (Wiens 1981, Likens 1989, Fuller et al. 1997, Holmes and Sherry 2001, Lovett et al. 2007, Lindenmayer and Likens 2010) and lead to the identification of ecological responses to temporal environmental variation that would not be possible in short-term studies or cross-sectional studies (Kruuk and Hill 2008). We acknowledge that there are many nuances to discussions about what constitutes "long-term" in longitudinal ecological research. Some workers consider long-term studies to be those that continue beyond the generation time of dominant organisms in an ecosystem or sufficiently long to quantify the key processes that shape the structure of the ecosystem under investigation (Strayer et al. 1986). This definition would mean that studies of bacterial assemblages with very rapid generation times would be long-term investigations if they persisted for a year or even a month. Our investigation was longer than the life span of most species of arboreal marsupials in the study area (typically 3-10 years), except for the mountain brushtail possum, which can live for up to 17 years. However, the maximum longevity of montane ash trees in our study system can exceed 500 years (Wood et al. 2010). Hence, our investigation could be considered as long term in the context of the animal species being targeted for study, but not for the dominant trees in montane ash forests. These considerations highlight the importance of continuing to maintain our work for many decades and hopefully longer.

In our investigation, longitudinal research led to several important new insights that were either: (1) unexpected because they did not conform or only partially conformed to the postulated responses we made at the outset based on earlier cross-sectional research, or (2) would not have been possible from a cross-sectional study. These new insights are further 
discussed in the remainder of this section and they include:

- No strong evidence for a decline in populations of almost all species of arboreal marsupials despite the loss of $>10 \%$ of the measured population of trees with hollows.

- Changes in nest tree selection by some species of arboreal marsupials in response to changes in hollow availability.

- Concentration effects, in which populations of animals used the declining tree hollow resource more intensively.

- An absence of tree fall effects on relationships between the abundance of trees with hollows and species richness, with no evidence of disproportionately negative impacts on particular elements of the biota, such as uncommon or rare species.

- Evidence for significant rainfall effects on temporal changes in animal abundance. This, in turn, enabled us to quantify background interannual variability in animal populations that affected biota independently of other spatiotemporal changes.

Altered patterns of tree decay and collapse.-Our longitudinal data indicated that the background assumption that tree fall rates would remain constant over time was breached. The mean percentage of hollowbearing trees lost per year between 1997 and 2007 (1.8\%) was considerably less than the percentage of trees with hollows lost between 1983 and 1993 (4.4\%) (Lindenmayer et al. 1997). Furthermore, our background assumption that the relationship between decay state and the probability of collapse would remain constant over time was only partially supported. Consistent with our earlier study, highly decayed trees were those most likely to collapse. However, the transition process between tree death and collapse (especially for trees in forms 6-9; see Table 2) was not as rapid in the 19972007 measurement period as it was in the earlier (19831993) measurement period (Lindenmayer et al. 1997). Thus, the composition of the population of hollowbearing trees was different from what was anticipated at the commencement of the study we have reported here. An additional interesting outcome of our work was the stochastic nature of tree collapse, with some standing living trees in the early stages of the decay process (i.e., trees in forms 1 and 2) collapsing to the forest floor without passing through tree forms corresponding to more advanced stages of deterioration (see Table 2). A range of reasons may explain these results, including individual tree characteristics that are not visible by external assessment (e.g., the extent of internal rot) but can nevertheless cause a tree to fail, and the influence of localized phenomena like windstorm events that damage living trees and/or result in them collapsing.

Other studies in forests where natural disturbances can be stand-replacing events have found that rates of tree fall follow a negative exponential pattern. The rate slows as an increasing proportion of the tree population is lost (e.g., Keen 1955, Shepherd 1957, Raphael and Morrison 1987, Gibbons et al. 2000). Our latest longterm data suggest that such patterns also may apply in montane ash forests, although it is interesting that the pulse of dead trees with hollows in these forests was created principally by the 1939 wildfires (Lindenmayer et al. 1991b), and our previous studies between 1983 and 1993 did not contain evidence of a slowing in the rates of collapse during that decade. We speculate that additional factors may have contributed to the slowing rates of tree fall in montane ash forests. An anecdotal observation during our longitudinal study has been that "wet" trees with hollows are those that appear to decay and collapse most rapidly. South-eastern Australia has experienced a prolonged dry period with many years of below-average rainfall during the past two decades (Cai and Cowan 2008). Trees are therefore now likely to be somewhat drier than they were during the early periods of this study. Future tests of annual tree fall rates would be valuable to determine if there is a relationship between rainfall and tree collapse. This underscores why longitudinal data sets are particularly important in studies of long-lived organisms such as large trees (Clarke et al. 1998, Ball et al. 1999), and in turn, for studies of those elements of the biota associated with them.

Adaptive animal responses to changes in tree availability.-Another insight derived from our longitudinal research that was not evident in our earlier crosssectional data was evidence for an adaptive response by arboreal marsupials to a change in the availability of trees with hollows. Indeed, this was an unexpected finding, as our previous work had underscored the relationships between the abundance of trees with hollows and the occurrence of animals on site (Lindenmayer et al. 1991d), and initial statistical relationships were found to perform well when tested on a new data set (Lindenmayer et al. 1994). However, our findings for an adaptive response to a change in the availability of trees with hollows was broadly consistent with findings by other workers on other groups of taxa showing that resource selection functions for a species can differ significantly over time, even in the same habitat (Boyce et al. 2002). Moreover, variation in the degree of flexibility in resource use can lead to contrasting responses among species to reductions in resource availability (Aitken and Martin 2008). Less-flexible species are predicted to decline with reduced resource availability, while those with greater flexibility will be less affected (Aitken and Martin 2008). In our longitudinal studies, we detected "relaxation" in tree selection, and hence greater flexibility in the selection of trees for den and nesting sites than was previously apparent from earlier cross-sectional work. Such flexible patterns of use were exhibited by some species (Leadbeater's possum and the mountain brushtail possum), but not others (the greater glider). 
As numbers of available trees with hollows declined and the composition of the types of trees with hollows in stands changed, relaxation in the types of trees selected by arboreal marsupials would allow them to partially compensate for the loss of trees with hollows on sites by using remaining trees more intensively, a "concentration effect" (Hypothesis 3 in the Introduction). Thus, in contrast to findings from our earlier cross-sectional work, the mountain brushtail possum and Leadbeater's possum showed no preference for any specific forms of trees with hollows, and they did not decline to the degree expected given the loss of trees with hollows that we documented on our sites. Unlike the results of earlier work (see Fig. 3), Leadbeater's possum also showed no significant relationship between the number of trees with hollows at a site and the abundance of the species. The reasons for this change in Leadbeater's possum remain unclear, but they may be associated with the preference of the species for young forests where trees with hollows are uncommon. Detailed long-term demographic and behavioral investigations are required to determine the mechanisms underpinning changes in relationships with the availability of trees with hollows. Indeed, long-term behavioral research on a single population of the mountain brushtail possum in the Central Highlands of Victoria (Banks et al. 2011) has suggested that the "concentration effect" observed in this study in response to the decline of trees with hollows is not one of increased den sharing among individuals, but rather an outcome of increased spacing of individuals among the remaining trees (resulting in a higher proportion of the trees at a site being occupied). Work by Banks et al. (2011) indicates that as hollow-tree availability declines and possible competition for these critical den resources increases, individuals of the mountain brushtail possum have become less tolerant of others and share dens less often. Kin selection also has developed in den-sharing interactions as these resources declined (Banks et al. 2011). Such a social response makes our finding of higher than expected "demographic resilience" to hollow-tree decline surprising, as reduced den sharing should exacerbate the negative impacts of reduced hollow-tree availability. However, the relaxation in tree selection that we observed by the mountain brushtail possum in this study may compensate for both the loss of older decayed hollow-bearing trees and the "antisocial response" of reduced den sharing under resource decline (Banks et al. 2011).

One species that did decline significantly in our study was the greater glider. The estimated annual rate of decline in this species was $8.8 \%$ per year. This compared with an annual rate of decline of trees with hollows of $1.8 \%$, and an annual rate of loss of $0.6 \%$ of trees in forms 1 and 2 (which are the preferred nest sites for this species). The greater glider did not exhibit relaxation in tree form selection, and maintained a strong association with tall living trees with hollows (forms 1-3; see Fig. 2). This pattern appears to be relatively inflexible, possibly because of the greater glider's gliding mode of movement that makes it reliant on tall, intact nest trees from which to commence volplaning (Jackson 1999, Lindenmayer 2002). Notably, this species' demand for tall, living trees with hollows makes it more vulnerable to the decay of these kinds of trees than to the overall rate of tree collapse, which includes losses of stems in advanced stages of deterioration, but which the glider does not use as nest sites.

Interactions between species are also considered to be an important contributor to observed patterns of resource selection (McLoughlin et al. 2009), and we found a signal of a potential interaction between tree use by the greater glider, tree decay, and other species. Sites where the greater glider declined also were those where the mountain brushtail possum increased (correlation coefficient $=-0.4 ; P<0.001)$. This effect was most prominent at those sites characterized by the greatest change in the condition of trees with hollows. Thus, as trees with hollows progress to later decay forms (see Fig. 2) they become less suitable for the greater glider.

Paucity of evidence for an overall temporal decline in populations of arboreal marsupials.-A third important and unexpected additional insight derived from our longitudinal research was that average stand-level animal abundance contained no significant evidence of decline for any species other than the greater glider (Fig. 8). Thus, the loss of many trees with hollows over the past decade has not been paralleled by a reduction in animal abundance to date despite: (1) trees with hollows being the sole nesting and denning sites for the majority of arboreal marsupials (Gibbons and Lindenmayer 2002), and (2) well-established relationships between animal abundance and the abundance of trees with hollows. The coefficients in tree hollow-animal abundance relationships developed using data gathered between 1997 and 2006 were not significantly different from those in the relationships from cross-sectional studies two decades earlier. However, for a number of species, the coefficient in the new relationship was smaller than previously found (Figs. 6 and 7), suggesting that animals are less sensitive now to the abundance of trees with hollows than they were previously. Possible reasons for the discrepancy between the predictions from the earlier cross-sectional work and the results of the longitudinal study include: (1) an adaptive response by hollow-dependent fauna (see Adaptive animal responses to changes in tree availability), and (2) previously unidentified influences such as rainfall (see Temporal effects of rainfall). We suggest that, based on our data for raw annual counts (Appendix: Table A1), and associated $95 \%$ confidence intervals (Fig. 8), a lack of statistical power is unlikely to explain a lack of detection of a decline in species like Leadbeater's possum and the sugar glider. Notably, counts for both species in any given year were often similar to those for the greater glider (Appendix: Table A1), which exhibited strong evidence for temporal decline (Fig. 8). However, both 
Leadbeater's possum and the sugar glider displayed significant interannual variation in numbers (Appendix: Table A1; Table 3, Fig. 8) and this has the potential to mask subtle population changes. Very long-term studies are needed to separate interannual variation from population decline, and this is the reason why our work is planned to continue for the coming 10-20 years.

It is possible that rarer species like the common ringtail possum, eastern pygmy possum, and feathertail glider may have declined during our study, but a paucity of data preclude drawing any robust conclusions about population trajectories for them. However, we found no evidence that uncommon or rare species were those most likely to be lost from sites with a decline in, and hence a reduced abundance of, trees with hollows. Thus, there was no evidence that common species competitively dominated sites with few trees with hollows.

We suggest there is likely to be a limit to how much the ongoing decline in the abundance of trees with hollows can be offset by either or both relaxation in tree selection by some species and by "concentration effects." These mechanisms may enable arboreal marsupials to respond to natural temporal variability in the availability of trees with hollows (see also Aitken and Martin 2008). It is possible that the numbers of trees with hollows observed across our study area remain within the natural range of hollow numbers in which these species of arboreal marsupials have evolved (Fig. 10). This is a reasonable assumption, because the principal form of natural disturbance in stands sampled in this study is high-severity wildfire. High-severity wildfires in these forests lead to the death of all trees in a stand, but the tree hollow resource is nevertheless perpetuated through the persistence of dead standing trees with hollows (Franklin et al. 2000). However, long-term sustained declines of hollow-bearing trees due to altered fire regimes or recurrent clear-cut logging operations may eventually exceed the capability of these behavioral "buffering" strategies in arboreal marsupials (Fig. 8). Work completed in forests overseas (e.g., Hartwig et al. 2004, Holloway and Malcolm 2007), as well as elsewhere in Australia, has indicated that some species of arboreal marsupials may alter their home ranges and patterns of nest and den tree use in response to resource availability, although there are limits to this (Lindenmayer et al. 2004, Pope et al. 2004). For example, species such as the greater glider maintain a minimum core home range area within which other conspecifics are generally excluded (Lindenmayer et al. 2004, Pope et al. 2004). In addition, for animals that live in pairs or can be solitary, like the mountain brushtail possum and the greater glider, a small set of primary den and nesting trees with hollows will be used frequently, and congeners will largely be excluded from occupying these trees (Lindenmayer et al. 1996b). On this basis, we plan to maintain our longitudinal studies beyond the current 10 years to determine if there are indeed limits to which arboreal marsupials can offset ongoing losses in trees

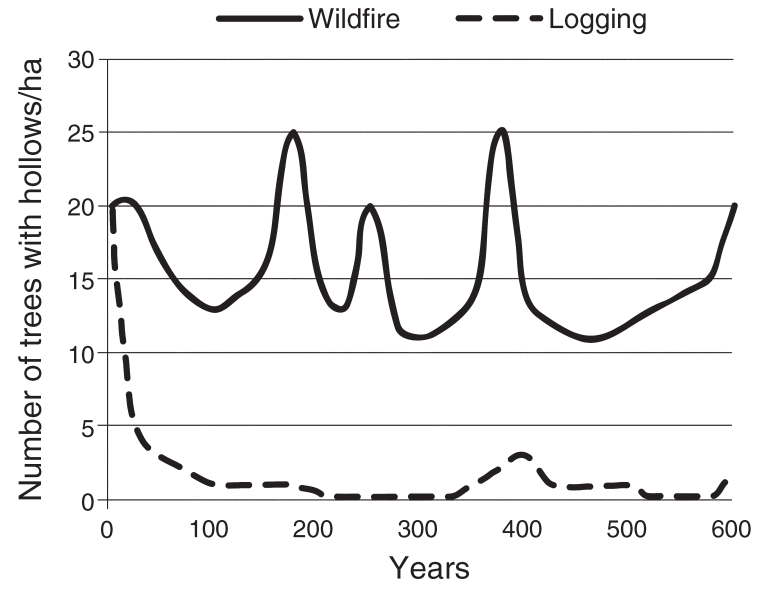

FIG. 10. Theoretical variation in numbers of trees with hollows in montane ash forests under a regime of natural wildfire (solid line) or logging (dashed line). In unlogged stands the numbers of trees with hollows peak after wildfire, the dead trees caused by the fire then decline, initially at a rapid rate, new trees with hollows begin to recruit after 120-150 years, and then the cycle is repeated with the next wildfire. In logged stands many hollow-bearing trees are pushed; retained hollow-bearing trees collapse at a rapid initial rate after the slash-burn, and new hollow-bearing trees are not generally recruited within the normal logging rotation (50-80 years).

with hollows and quantify the nature of animal responses to conditions where the extent of tree fall exceeds, for example, $>20 \%$ of the 1997 hollow-tree population. That is, levels of tree loss that are more than double what has occurred over the past decade. For example, it is possible that there may be critical break points or thresholds (sensu Huggett 2005, Groffman et al. 2006) in tree hollow :animal abundance relationships that limit the effectiveness of concentration and flexible tree selection, and below which species cannot persist.

Temporal effects of rainfall.-A new insight from our longitudinal research was the establishment of relationships between rainfall and interannual variability in the total abundance of arboreal marsupials per se, and specifically for the sugar glider and the greater glider. Many factors may underpin such temporal fluctuations in the abundance of animals, but interannual variation in the availability of food (e.g., nectar, pollen, and insects) is often an important driver (e.g., Wiens 1989, Recher et al. 1996), and it is likely to have contributed to the patterns we observed, such as for the exudivorous and insectivorous sugar glider. In the case of the greater glider, which is a specialist folivore with a diet composed almost entirely of eucalypt leaves, it is possible that reduced levels of rainfall may alter the suitability of leaves as a food source for the species. We speculate that rainfall effects on food resources may have, in turn, been associated with breeding success or survival (e.g., see Banks et al. 2008). This was because we conducted our field surveys of animals in late spring and summer when the semi-independent or independent young of most species were on sites and would be counted in 


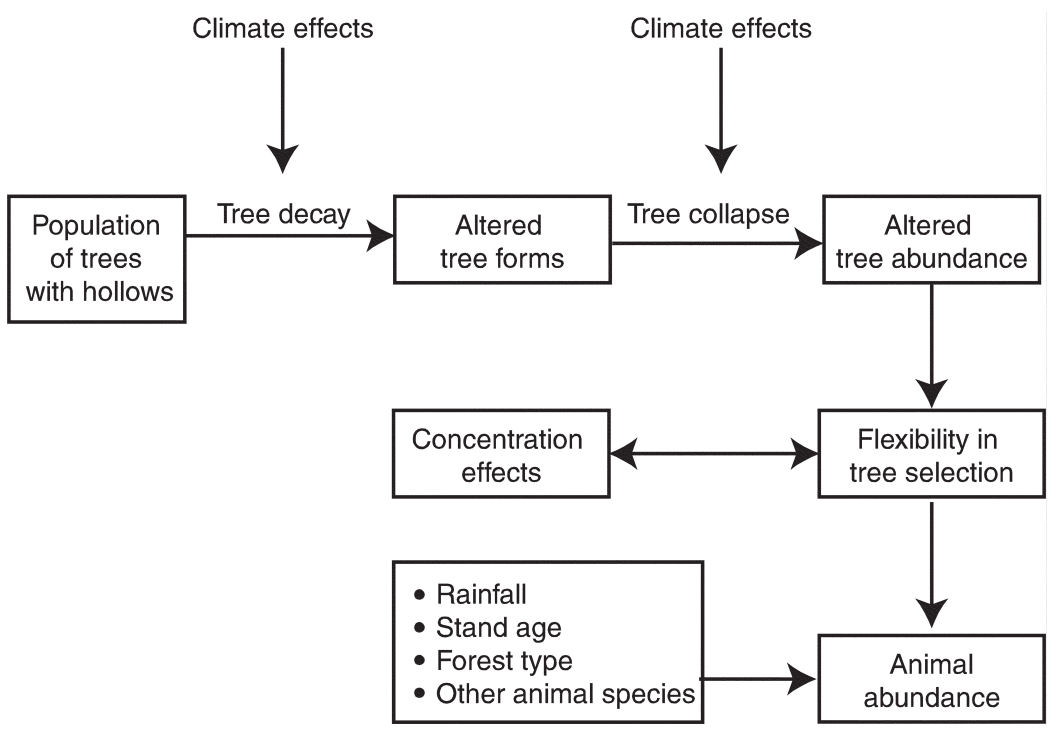

FIG. 11. A simple conceptual model of hypothesized relationships between the tree hollow development, decay, and availability, the abundance of arboreal marsupials, and other factors at the site and tree level that can influence animal occurrence and abundance.

stagwatching surveys. This also may explain the twoyear time delay in rainfall response in the Greater Glider, an animal that breeds less frequently (typically biannually) than most other species of arboreal marsupials (Lindenmayer 2002, Tyndale-Biscoe 2005).

\section{A new conceptual model of hollow-tree resources and arboreal marsupial populations}

Conceptual models are critically important for guiding long-term ecological research and monitoring (e.g., Bormann and Likens 1967) because they motivate the development of key questions and hypotheses for subsequent testing (Nichols and Williams 2006, Lindenmayer and Likens 2010). In many respects, Figs. 1-3 in the Introduction section of this paper have acted as conceptual "submodels" reflecting different areas of understanding about hollow-tree : animal response relationships. New insights obtained from the longitudinal studies we report here have helped better integrate different areas of understanding, leading to a revised conceptual model that incorporates updated thinking about the relationships between tree hollow decay and availability, the abundance of arboreal marsupials, and other factors at the tree and stand levels that can influence animal occurrence and abundance (Fig. 11). Part of this new conceptual model emphasizes the influence of multiple factors at a range of spatial and temporal scales on the distribution and abundance of particular species (see also Forman 1964, Diamond 1973, Schneider 1994, Levin 2009).

We plan to use the new conceptual model in Fig. 11 as part of continuing our examination of temporal and spatial relationships between hollow-tree availability and animal abundance. Our aim is to monitor tree and animal populations, and relationships between them, over the coming decade when $\sim 20 \%$ or more of the 1997 measured population of trees with hollows is projected to be lost (Fig. 5). We postulate that either of two markedly different kinds of responses to declining tree hollow resources might occur. One is that there is a threshold level for the abundance of trees with hollows, below which particular species of animals are unable to persist (Newton 1994, Gibbons and Lindenmayer 2002). The alternative is that ongoing decline in the abundance of trees with hollows leads to an approximately linear decline in the abundance of animals (after accounting for other spatial and temporal factors that influence animal abundance). Which of these two kinds of response occur will matter for informed forest management and biodiversity conservation. For example, if it is a threshold response, then it will be crucial to manage tree hollow populations at levels well above critical break points (Walker and Salt 2006). The existence of such thresholds would, in turn, have implications for timber-harvesting prescriptions associated with the maintenance of existing, and recruitment of new, large trees with hollows within wood production forests. We further discuss some of the practical implications of our work in the following section.

\section{Future animal abundance}

As part of past work (Lindenmayer et al. 1997), we made population projections of arboreal marsupials for the period 1997 to ca. 2060 , by linking statistical models of animal relationships with the abundance of trees with hollows with previously quantified rates of collapse of trees with hollows. We previously forecast a steep (30$40 \%$ ) decline in populations of the greater glider, the mountain brushtail possum, and Leadbeater's possum between 1997 and 2010 as a consequence of the loss of 

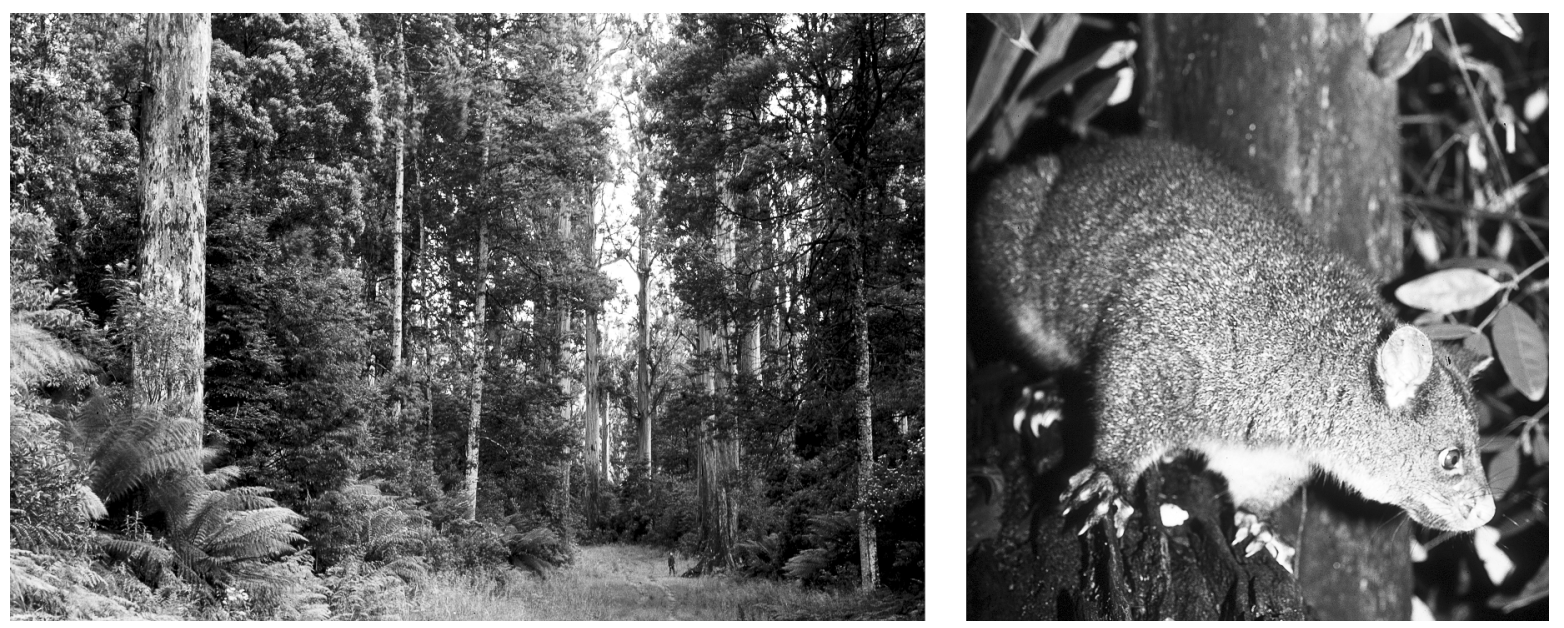

Plate 1. (Left) Old-growth mountain ash forest; the person seen on the right indicates scale, i.e. the colossal size of the trees; (right) mountain brushtail possum. Photo credits: D. B. Lindenmayer.

trees with hollows (Lindenmayer et al. 1997). We note the substantial differences between those previous projected declines in populations of arboreal marsupials and the results of this longitudinal study, in particular: (1) short-term (1997-2007) fluctuations in average stand-level animal abundance that contained no significant current evidence of decline for most species (Fig. 8 ), and (2) the more rapid decline in the numbers of the greater glider, which can be explained by a loss of trees with hollows. These differences are likely to be due to factors that were overlooked by Lindenmayer et al. (1997) in making previous long-term projections. They underscore the potential risks of making long-term predictions from short-term data, and hence the critical need to continue longitudinal studies for a prolonged period. In the particular case of our research, this would allow us to determine if the relatively short-term patterns shown in Fig. 8 begin to resemble the longerterm trends projected in Lindenmayer et al. (1997). Even if this does not occur, the decline in numbers of trees with hollows that we have projected to occur over the next 40 years (Fig. 5) is highly likely to have an impact on the abundance of arboreal marsupials.

Finally, a key part of future animal monitoring work will be to differentiate between short term-behavioral responses and longer-term demographic responses, including the identification of the varying capacity of different species to adapt to, or take advantage of, habitat changes. An important component of such work will be to significantly improve the currently poor understanding of the demography of various species of arboreal marsupials, as it may have implications for decisions about the ways in which habitats are managed.

\section{Forest and wildlife management implications}

Several of the findings of this investigation are of broad relevance for informed forest management and improved forest biodiversity conservation. This is because ecological problems created by a shortage of large trees, including trees with hollows, are common to many vegetation types worldwide (Newton 1994) including those in North America (Fischer and McClelland 1983, Franklin et al. 2002, Fenger et al. 2006, Lutz et al. 2009, Smith et al. 2009), South America (Oliveira et al. 2008, Venturieri 2009), Europe (Fries et al. 1997, Linder and Östlund 1998, Ranius et al. 2009), Asia (Eltz et al. 2003, Lohmus 2003), and Australia (Gibbons and Lindenmayer 2002, Crane et al. 2010). One of the ways in which these problems manifest is the decline of biota associated with trees with hollows (Newton 1994, 1998, Fenger et al. 2006, Perry et al. 2008, Bunnell and Dunsworth 2009). Thus, the issues of maintaining populations of trees with hollows and cavity-associated biota in forests around the globe are broadly similar to those in montane ash forests. However, solutions to problems of a shortage of trees with hollows must be evidence based (sensu Sutherland et al. 2004) for them to be effective, because inappropriate decisions can have negative consequences for many decades or even centuries (Linder and Östlund 1998, Gibbons and Lindenmayer 2002, Newsom et al. 2006). Given the results of this study, we argue that informed decisions need to be based at least on: (1) an understanding of the dynamics of decay and collapse (as well as recruitment) of trees with hollows, (2) the importance of such trees in rigorously quantified habitat relationships for wildlife of conservation concern, (3) an understanding of temporal and spatial patterns of hollow-tree usage by target wildlife species, and (4) links between 1-3 as exemplified, in part, by the conceptual model shown in Fig. 11.

Understanding the dynamics of decay, collapse, and recruitment of trees with hollows is crucial in all forests. This is because the problems created by asymmetry between the rapidity with which large trees can be removed over extensive areas, but the prolonged time that must elapse for them to regrow, are common to 
many kinds of forests worldwide (Franklin et al. 1981, van Pelt 2007, Gibbons et al. 2008, Lutz et al. 2009). They are particularly acute in forests dominated by young, regenerating regrowth stands and where major disturbances are stand-replacing events (reviewed in Lindenmayer and Franklin 2002). Montane ash forests exemplify these problems, as tree fall rates are relatively rapid and the vast majority of current stands are either regenerating after fires in 1939 and 1983 (and most recently 2009) or have been clear-cut in the past 50 years (Lindenmayer 2009). In extensive stands of 1939 regrowth montane ash forest, we estimate that it will take until at least 2050-2060 before existing trees in these areas begin to develop hollows suitable for occupancy by some species of cavity-dependent animals (Lindenmayer et al. 1993b). For those species of arboreal marsupials typically associated with large cavities (e.g., the greater glider), suitable hollows may not form until 2090-2140 (Smith and Lindenmayer 1988). Hence, there may be large areas of 1939 regrowth forest in the Central Highlands of Victoria where habitat suitability for cavity-dependent fauna will be impaired for many decades into the future. However, our longitudinal data demonstrating slowing rates of tree collapse and decay mean that more trees with hollows are likely to persist (and persist for longer) in regrowth montane ash forests, which may help life-boat (sensu Franklin et al. 1997) populations of some species of cavity-dependent animals for longer than projected in earlier studies (Lindenmayer et al. 1997).

Much has been written about the importance of oldgrowth forest in natural resource management and biodiversity conservation over the past three decades (e.g., Franklin et al. 1981, Hunter 1999, Perry et al. 2008). Our study suggests that one of the reasons that old-growth stands are important to target for conservation management is that they support significantly more large living trees (forms $1-2$ in Fig. 2) than younger stands (Lindenmayer et al. 2000). These trees have a greater probability of remaining standing over time than dead standing trees (Table 2), and hence old-growth montane ash stands are likely to assume increasing importance over time as habitat for cavity-dependent animals like arboreal marsupials.

The risk of interactions between potential stressors is an additional reason why the protection of old-growth stands is important. Our longitudinal study highlighted relationships between rainfall and the abundance of some species of arboreal marsupials. A major decline in annual rainfall over the past 25 years has characterized much of southeastern Australia (Cai and Cowan 2008). If drying effects are associated with climate change, as has been forecast in regions such as southeastern Australia (Steffen et al. 2009), then although rates of tree fall might be slowed (but nevertheless still substantial), forest carrying capacity for some species may be reduced. This suggests that some cavity-dependent organisms may be faced with substantive interacting threatening processes, an ongoing decline in the abundance of trees with hollows together with continued climate drying. This further underscores the importance of conserving places like old-growth forest where at least one of these stressors, the loss of trees with hollows, will be less pronounced. Current management strategies in montane ash forests have exempted old-growth and multi-aged stands from timber harvesting, and our data suggest that the maintenance of this policy initiative is important.

As we outlined above, an understanding of temporal and spatial patterns of hollow-tree usage by target wildlife species can be important for informed forest and wildlife management and changing widespread traditional practices like prescriptions for tree retention. For example, in the case of montane ash forests, although trees with hollows are protected by forestry prescriptions, clear-cut logging operations adjacent to these trees accelerates their decay and collapse (Ball et al. 1999, Gibbons et al. 2000). We argue that trees in these areas need to be given greater protection than they are currently because of new evidence for concentration effects and relaxation of tree selection which, in turn, suggest that remaining trees with hollows in regrowth montane ash forests may assume increasing importance for the local persistence of arboreal marsupials.

Within temperate forests where logging is permitted, a widespread approach to promote the retention of existing large trees and promote the recruitment of new ones has been to apply modified silvicultural systems like the Variable Retention Harvest System (sensu Franklin et al. 1997) as an alternative to traditional clear-cut logging. There is a broadly parallel body of work in tropical forests (viz. Reduced Intensity Logging (RIL) (Putz et al. 2008)). There are many studies of the effectiveness of variable retention or green-tree retention harvesting in temperate forests (Vanderwel et al. 2007, Bunnell and Dunsworth 2009), but general findings from these studies to date are equivocal. On this basis, we have recently commenced trials of the Variable Retention Harvest System to retain islands of forest within logged areas of 1939 regrowth montane ash forest so they may provide future habitat for arboreal marsupials as well as other cavity-dependent vertebrate fauna (Lindenmayer et al. 2010).

Finally, a possible solution to the problem of a shortage of trees with hollows in many kinds of forests worldwide has been to install artificial cavities such as nest boxes (Newton 1998, Harper et al. 2005, Beyer and Goldingay 2006). This has sometimes been remarkably successful (e.g., Bruns 1960, Taulman et al. 1998). However, this approach may have limitations, as illustrated by earlier work we have completed in montane ash forests. We conducted a 10 -year nest box program in montane ash forests and it proved to be ineffective, with very low rates of occupancy by targeted taxa, including arboreal marsupials (Lindenmayer et al. 2009). This suggests that in these forests, nest boxes are 
poor proxies for naturally occurring hollows, with some key attributes of the latter, like insulative properties, not being adequately replicated in artificial cavities. These results have implications for proposed experiments where nest boxes might be added to forest stands in an attempt to manipulate low, medium, or high levels of cavity availability for arboreal marsupials. The many nest boxes we have established over the past 10 years in montane ash forests $(N=196)$ also have experienced both considerable rates of attrition within a relatively short period (less than eight years following installation) and high levels of infestation by pest invertebrates (Lindenmayer et al. 2009). This combination of problems suggest that research in which trees are deliberately injured to promote cavity formation (e.g., Bull and Partridge 1981, Chambers et al. 1997, Rose et al. 2001) may need to be expanded to new forest types like those dominated by stands of montane ash trees.

\section{ACKNOWLedgments}

This project has been supported by many organizations over the past 10 years, particularly the Australian Government Department of the Environment, Water, Heritage and the Arts, Victorian Government Department of Sustainability and Environment, and Parks Victoria, all of which have operated under different names in that time. In addition, grants from the Australian Research Council and the Thomas Foundation have been critical to ensuring that this work could continue. A large number of dedicated volunteers from the Earthwatch Institute and the general public have assisted in counts of arboreal marsupials on our monitoring sites over the past two decades. Insightful comments by several anonymous referees greatly improved earlier versions of this manuscript.

\section{Literature Cited}

Aitken, K. E. H., and K. Martin. 2008. Resource selection plasticity and community responses to experimental reduction of a critical resource. Ecology 89:971-980.

Ambrose, G. J. 1982. An ecological and behavioural study of vertebrates using hollows in eucalypt branches. Dissertation. La Trobe University, Melbourne, Victoria, Australia.

Ashton, D. H. 1975. The root and shoot development of Eucalyptus regnans F. Muell. Australian Journal of Botany 23:867-887.

Ashton, D. H. 1976. The development of even-aged stands of Eucalyptus regnans $\mathrm{F}$. Muell. in central Victoria. Australian Journal of Botany 24:397-414.

Ashton, D. H. 1981. Fire in tall open forests (wet sclerophyll forests). Pages 339-366 in A. M. Gill, R. H. Groves, and I. R. Noble, editors. Fire and the Australian biota. Australian Academy of Science, Canberra, A.C.T., Australia.

Bai, M., and M. Muhlenberg. 2008. Sequential use of holes by birds breeding in a natural boreal forest in Mongolia. Bird Study 55:161-168.

Ball, I. R., D. B. Lindenmayer, and H. P. Possingham. 1999. A tree hollow dynamics simulation model. Forest Ecology and Management 123:179-194.

Banks, S. C., E. J. Knight, J. E. Dubach, and D. B. Lindenmayer. 2008. Microhabitat heterogeneity influences offspring sex allocation and spatial kin structure in possums. Journal of Animal Ecology 77:1250-1256.

Banks, S. C., D. B. Lindenmayer, L. McBurney, D. Blair, E. J. Knight, and M. D. J. Blyton. 2011. Kin selection in den sharing develops under limited availability of tree hollows for a forest marsupial. Proceedings of the Royal Society B [doi: $10.1098 / \mathrm{rspb} .2010 .2657]$
Beyer, G. L., and R. L. Goldingay. 2006. The value of nest boxes in the research and management of Australian hollowusing arboreal marsupials. Wildlife Research 33:161-174.

Bormann, F. H., and G. E. Likens. 1967. Nutrient cycling. Science 155:424-429.

Boyce, M. S., P. R. Vernier, S. E. Nielsen, and F. K. A. Schmiegelow. 2002. Evaluating resource selection functions. Ecological Modelling 157:281-300.

Bruns, H. 1960. The economic importance of birds in forests. Bird Study 7:193-208.

Bull, E. L., and A. D. Partridge. 1981. Creating snags with explosives. USDA Forest Service Research Note PNW 393. Pacific Northwest Forest and Range Station, Portland, Oregon, USA.

Bunnell, F., and G. B. Dunsworth, editors. 2009. Forestry and biodiversity. Learning how to sustain biodiversity in managed forests. UBC Press, Vancouver, British Columbia, USA.

Cai, W., and T. Cowan. 2008. Dynamics of late autumn rainfall reduction over southeastern Australia. Geophysical Research Letters 35:L09708 [doi:09710.01029/02008GL033727]

Chambers, C. L., T. Carrigan, T. Sabin, J. Tappeiner, and W. C. McComb. 1997. Use of artificially created Douglas-fir snags by cavity-nesting birds. Western Journal of Applied Forestry 12:93-97.

Clarke, M., R. Sukumar, S. P. Hubbell, and R. B. Foster. 1998. Predicting population trends from size distributions: a direct test in a tropical tree community. American Naturalist 152:495-509.

Cline, S. P., A. B. Berg, and H. M. Wight. 1980. Snag characteristics and dynamics in Douglas fir forests, western Oregon. Journal of Wildlife Management 44:773-786.

Crane, M., D. B. Lindenmayer, and R. B. Cunningham. 2010. The use of den trees by the squirrel glider (Petaurus norfolcensis) in temperate Australian woodlands. Australian Journal of Zoology 58:39-49.

Crane, M., R. M. Montague-Drake, R. B. Cunningham, and D. B. Lindenmayer. 2008. The characteristics of den trees used by the Squirrel Glider (Petaurus norfolcensis) in temperate Australian woodlands. Wildlife Research 35:663-675.

Diamond, J. M. 1973. Distributional ecology of New Guinea birds. Science 179:759-769.

Diamond, J. M. 1986. Overview: laboratory experiments, field experiments and natural experiments. Pages 3-22 in J. M. Diamond and T. J. Case, editors. Community ecology. Harper and Row, New York, New York, USA.

Dick, R. S. 1975. A map of Australia according to Koppen's principles of definition. Queensland Geographic Journal (Third Series) 3:33-69.

Elton, C. S. 1927. Animal ecology. Sidgwick and Jackson, London, UK.

Eltz, T., C. A. Bruhl, Z. Imiyabir, and K. E. Linsenmair. 2003. Nesting and nest trees of stingless bees (Apidae: Meliponini) in lowland dipterocarp forests in Sabah, Malaysia, with implications for forest management. Forest Ecology and Management 172:301-313.

Fenger, M., T. Manning, J. Cooper, S. Guy, and P. Bradford. 2006. Wildlife and trees in British Columbia. Lone Pine Publishing, Edmonton, Alberta, Canada.

Fischer, W. C., and B. R. McClelland. 1983. Cavity-nesting bird bibliography including related titles on forest snags, fire, insects, diseases and decay. General Technical Report INT140, Intermountain Forest and Range Experiment Station, Ogden, Utah, USA.

Forman, R. T. 1964. Growth under controlled conditions to explain the hierarchical distributions of a moss, Tetraphis pellucida. Ecological Monographs 34:1-25.

Franklin, J. F., D. E. Berg, D. A. Thornburgh, and J. C. Tappeiner. 1997. Alternative silvicultural approaches to timber harvest: variable retention harvest systems. Pages 111-139 in K. A. Kohm and J. F. Franklin, editors. Creating 
a forestry for the 21 st century. Island Press, Covelo, California, USA.

Franklin, J. F., K. J. Cromack, W. Denison, A. McKee, C. Maser, J. Sedell, F. Swanson, and G. Juday. 1981. Ecological attributes of old-growth Douglas-fir forests. General Technical Report PNW-GTR-118, Pacific Northwest Forest and Range Experiment Station, Portland, Oregon, USA.

Franklin, J. F., D. B. Lindenmayer, J. A. MacMahon, A. McKee, J. Magnuson, D. A. Perry, R. Waide, and D. R. Foster. 2000. Threads of continuity: ecosystem disturbances, biological legacies and ecosystem recovery. Conservation in Practice 1:8-16.

Franklin, J. F., T. A. Spies, R. van Pelt, A. B. Carey, D. A. Thornburgh, D. R. Berg, D. B. Lindenmayer, M. Harmon, W. Keeton, and D. C. Shaw. 2002. Disturbances and the structural development of natural forest ecosystems with some implications for silviculture. Forest Ecology and Management 155:399-423.

Fries, C., O. Johansson, B. Petterson, and P. Simonsson. 1997. Silvicultural models to maintain and restore natural stand structures in Swedish boreal forests. Forest Ecology and Management 94:89-103.

Fuller, R. J., R. J. Trevelyan, and R. W. Hudson. 1997. Landscape composition models for breeding bird populations in lowland English farmland over a 20 -year period. Ecography 20:295-307.

Gibbons, P., and D. B. Lindenmayer. 2002. Tree hollows and wildlife conservation in Australia. CSIRO Publishing, Melbourne, Victoria, Australia.

Gibbons, P., D. B. Lindenmayer, S. C. Barry, and M. T. Tanton. 2000. The effects of slash burning on the mortality and collapse of trees retained on logged sites in south-eastern Australia. Forest Ecology and Management 139:51-61.

Gibbons, P., D. B. Lindenmayer, J. Fischer, A. D. Manning, A. Weinberg, J. Sedden, P. Ryan, and G. Barrett. 2008. The future of scattered trees in agricultural landscapes. Conservation Biology 22:1309-1319.

Groffman, P. M., et al. 2006. Ecological thresholds: The key to successful environmental management or an important concept with no practical application? Ecosystems 9:1-13.

Guisan, A., and W. Thuiller. 2005. Predicting species distribution: offering more than simple habitat models. Ecology Letters 8:993-1009.

Guisan, A., and N. E. Zimmerman. 2000. Predictive habitat distribution models in ecology. Ecological Modelling 135:147-186.

Haila, Y., A. O. Nicholls, I. K. Hanski, and S. Raivio. 1996. Stochasticity in bird habitat selection: year-to-year changes in territory locations in a boreal forest bird assemblage. Oikos 76:536-552.

Hall, L. S., P. A. Krausman, and M. L. Morrison. 1997. The habitat concept and a plea for the use of standard terminology. Wildlife Society Bulletin 25:173-182.

Harper, M. J., M. A. McCarthy, and R. van der Ree. 2005. The use of nest boxes in urban natural vegetation remnants by vertebrate fauna. Wildlife Research 32:509-516.

Hartwig, C. L., D. S. Eastman, and A. S. Harestad. 2004. Characteristics of pileated woodpecker (Dryocopus pileatus) cavity trees and their patches on southeastern Vancouver Island, British Columbia, Canada. Forest Ecology and Management 187:225-234.

Holloway, G. L., and J. R. Malcolm. 2007. Nest-tree use by northern and southern flying squirrels in central Ontario. Journal of Mammalogy 88:226-233.

Holmes, R. T., and T. W. Sherry. 2001. Thirty-year bird population trends in an unfragmented temperate deciduous forest: importance of habitat change. Auk 118:589-609.

Huggett, A. J. 2005. The concept and utility of 'ecological thresholds' in biodiversity conservation. Biological Conservation 124:301-310.
Hunter, M. L. 1990. Wildlife, forests and forestry. Principles for managing forests for biological diversity. Prentice Hall, Englewood Cliffs, New Jersey, USA.

Hunter, M. L. 1999. Managing biodiversity in forest ecosystems. Cambridge University Press, London, UK.

Jackson, S. T. 1999. Glide angle in the genus Petaurus and a review of gliding in mammals. Mammal Review 30:9-30.

Keen, F. P. 1955. The role of natural falling of beetle-killed ponderosa pine snags. Journal of Forestry 27:720-723.

Keeton, W. S. 2006. Managing for late-successional old-growth characteristics in northern hardwood-conifer forests. Forest Ecology and Management 235:129-142.

Krebs, C. J., S. Boutin, and R. Boonstra, editors. 2001. Ecosystem dynamics of the boreal forest: the Kluane project. Oxford University Press, New York, New York, USA.

Kruuk, L., and W. G. Hill. 2008. Evolutionary dynamics of wild populations: the use of long-term pedigree data. Proceedings of the Royal Society B 275:593-596.

Lee, Y., J. A. Nelder, and Y. Pawitan. 2006. Generalized Linear Models with Random Effects: unified analysis via hlikelihood. Chapman and Hall/CRC, Boca Raton, Florida, USA.

Levin, S. A., editor. 2009. The Princeton guide to ecology. Princeton University Press, Princeton, New Jersey, USA.

Likens, G. E., editor. 1989. Long-term studies in ecology. Approaches and alternatives. Springer-Verlag, New York, New York, USA.

Lindenmayer, D. B. 1997. Differences in the biology and ecology of arboreal marsupials in forests of southeastern Australia. Journal of Mammalogy 78:1117-1127.

Lindenmayer, D. B. 2002. Gliders of Australia. A natural history. UNSW Press, Sydney, New South Wales, Australia.

Lindenmayer, D. B. 2009. Forest pattern and ecological process: a synthesis of 25 years of research. CSIRO Publishing, Melbourne, Victoria, Australia, USA.

Lindenmayer, D. B., and M. A. Burgman. 2005. Practical conservation biology. CSIRO Publishing, Melbourne, Victoria, Australia.

Lindenmayer, D. B., S. A. Craig, T. Linga, and M. T. Tanton. 1991a. Public participation in stagwatching surveys for a rare mammal - applications for environmental education. Australian Journal of Environmental Education 7:63-70.

Lindenmayer, D. B., R. B. Cunningham, and C. F. Donnelly. 1993a. The conservation of arboreal marsupials in the montane ash forests of the Central Highlands of Victoria, South-east Australia: IV. The presence and abundance of arboreal marsupials in retained linear habitats (wildlife corridors) within logged forest. Biological Conservation 66:207-221.

Lindenmayer, D. B., R. B. Cunningham, and C. F. Donnelly. 1994. The conservation of arboreal marsupials in the montane ash forests of the Central Highlands of Victoria, South-Eastern Australia: VI. the performance of statistical models of the nest tree and habitat requirements of arboreal marsupials applied to new survey data. Biological Conservation 70:143-147.

Lindenmayer, D. B., R. B. Cunningham, and C. F. Donnelly. 1997. Decay and collapse of trees with hollows in eastern Australian forests: impacts on arboreal marsupials. Ecological Applications 7:625-641.

Lindenmayer, D. B., R. B. Cunningham, C. F. Donnelly, and J. F. Franklin. 2000. Structural features of old growth Australian montane ash forests. Forest Ecology and Management 134:189-204.

Lindenmayer, D. B., R. B. Cunningham, C. F. Donnelly, M. T. Tanton, and H. A. Nix. 1993b. The abundance and development of cavities in eucalyptus trees: a case-study in the montane forests of Victoria, Southeastern Australia. Forest Ecology and Management 60:77-104.

Lindenmayer, D. B., R. B. Cunningham, C. MacGregor, and R. D. Incoll. 2003. A long-term monitoring study of the 
population dynamics of arboreal marsupials in the Central Highlands of Victoria. Biological Conservation 110:161-167. Lindenmayer, D. B., R. B. Cunningham, H. A. Nix, M. T. Tanton, and A. P. Smith. 1991b. Predicting the abundance of hollow-bearing trees in montane ash forests of south-eastern Australia. Australian Journal of Ecology 16:91-98.

Lindenmayer, D. B., R. B. Cunningham, M. T. Tanton, and H. A. Nix. 1991c. Aspects of the use of den trees by arboreal and scansorial marsupials inhabiting montane ash forests in Victoria. Australian Journal of Zoology 39:57-65.

Lindenmayer, D. B., R. B. Cunningham, M. T. Tanton, H. A. Nix, and A. P. Smith. 1991d. The conservation of arboreal marsupials in the montane ash forests of the Central Highlands of Victoria, South-East Australia: III. The habitat requirements of Leadbeater's possum Gymnobelideus leadbeateri and models of the diversity and abundance of arboreal marsupials. Biological Conservation 56:295-315.

Lindenmayer, D. B., R. B. Cunningham, M. T. Tanton, and A. P. Smith. 1990a the conservation of arboreal marsupials in the montane ash forests of the central highlands of Victoria, Southeast Australia: II. the loss of trees with hollows and its implications for the conservation of Leadbeater's possum Gymnobelideus leadbeateri McCoy (Marsupialia: Petauridae). Biological Conservation 54:133145.

Lindenmayer, D. B., R. B. Cunningham, M. T. Tanton, A. P. Smith, and H. A. Nix. 1990b. The conservation of arboreal marsupials in the montane ash forests of the Central Highlands of Victoria, Southeast Australia: I. factors influencing the occupancy of trees with hollows. Biological Conservation 54:111-131.

Lindenmayer, D. B., R. B. Cunningham, M. T. Tanton, A. P. Smith, and H. A. Nix. 1990c. The habitat requirements of the Mountain Brushtail Possum and the Greater Glider in the montane ash-type eucalypt forests of the Central Highlands of Victoria. Australian Wildlife Research 17:467-478.

Lindenmayer, D. B., R. B. Cunningham, M. T. Tanton, A. P. Smith, and H. A. Nix. 1991e. Characteristics of hollowbearing trees occupied by arboreal marsupials in the montane ash forests of the Central Highlands of Victoria, south-east Australia. Forest Ecology and Management 40:289-308.

Lindenmayer, D. B., and J. F. Franklin. 2002. Conserving forest biodiversity: a comprehensive multiscaled approach. Island Press, Washington, USA.

Lindenmayer, D. B., E. Knight, L. McBurney, D. Michael, and S. C. Banks. 2010. Small mammals and retention islands: an experimental study of animal response to alternative logging practices. Forest Ecology and Management 260:2070-2078.

Lindenmayer, D. B., and G. E. Likens. 2010. Effective ecological monitoring. CSIRO Publishing and Earthscan, Melbourne, Victoria, Australia.

Lindenmayer, D. B., C. MacGregor, A. W. Welsh, C. F. Donnelly, and D. Brown. 2008. The use of hollows and dreys by the common ringtail possum (Pseudocheirus peregrinus) in different vegetation types. Australian Journal of Zoology $56: 1-11$

Lindenmayer, D. B., B. Mackey, and H. A. Nix. $1996 a$. Climatic analyses of the distribution of four commerciallyimportant wood production eucalypt trees from southeastern Australia. Australian Forestry 59:11-26.

Lindenmayer, D. B., and R. A. Meggs. 1996. Use of den trees by Leadbeater's Possum (Gymnobelideus leadbeateri). Australian Journal of Zoology 44:625-638.

Lindenmayer, D. B., M. L. Pope, and R. B. Cunningham. 2004. Patch use by the greater glider (Petauroides volans) in a fragmented forest ecosystem. II. Characteristics of den trees and preliminary data on den-use patterns. Wildlife Research 31:569-577.

Lindenmayer, D. B., A. Welsh, C. F. Donnelly, M. Crane, D. Michael, C. MacGregor, L. McBurney, R. M. MontagueDrake, and P. Gibbons. 2009. Are nest boxes a viable alternative source of cavities for hollow-dependent animals? Long-term monitoring of nest box occupancy, pest use and attrition. Biological Conservation 142:33-42.

Lindenmayer, D. B., A. Welsh, C. F. Donnelly, and R. A. Meggs. 1996b. Use of nest trees By the Mountain Brushtail Possum (Trichosurus caninus) (Phalangeridae, Marsupialia). 1. Number of occupied trees and frequency of tree use. Wildlife Research 23:343-361.

Lindenmayer, D. B., and J. T. Wood. 2010. Long-term patterns in the decay, collapse, and abundance of trees with hollows in the mountain ash (Eucalyptus regnans) forests of Victoria, southeastern Australia. Canadian Journal of Forest Research 40:48-54.

Linder, P., and L. Östlund. 1998. Structural changes in three mid-boreal Swedish forest landscapes, 1885-1996. Biological Conservation 85:9-19.

Lohmus, A. 2003. Do Ural owls (Strix uralensis) suffer from a lack of nest sites in managed forests? Biological Conservation 110:1-9.

Lovett, G. M., D. A. Burns, C. T. Driscoll, J. C. Jemkins, M. J. Mitchell, L. Rustad, J. B. Shanley, G. E. Likens, and R. Haeuber. 2007. Who needs environmental monitoring? Frontiers in Ecology and the Environment 5:253-260.

Lutz, J. A., J. W. van Wagtendonk, and J. F. Franklin. 2009. Twentieth-century decline of large-diameter trees in Yosemite National Park, California, USA. Forest Ecology and Management 257:2296-2307.

Margules, C. R., and M. P. Austin, editors. 1991. Nature conservation: cost effective biological surveys and data analysis. CSIRO, Canberra, A.C.T., Australia.

Maron, M., A. Lill, D. M. Watson, and R. MacNally. 2005. Temporal variation in bird assemblages: How representative is a one-year snapshot? Austral Ecology 30:383-394.

McCullagh, P., and J. A. Nelder. 1989. Generalized Linear Models. Second edition. Chapman and Hall, New York, New York, USA.

McCulloch, C. E., and S. R. Searle. 2001. Generalized, Linear, and Mixed Models. Wiley, New York, New York, USA.

McGarigal, K., and S. A. Cushman. 2002. Comparative evaluation of experimental approaches to the study of fragmentation studies. Ecological Applications 12:335-345.

McLoughlin, P. D., D. W. Morris, D. Fortin, E. Vander Wal, and A. L. Contasti. 2009. Considering ecological dynamics in resource selection functions. Journal of Animal Ecology $79: 4-12$.

Morrison, M. L., B. G. Marcot, and R. W. Mannan. 2006. Wildlife-habitat relationships. Concepts and applications. Island Press, Washington, D.C., USA.

Newsom, D., V. Bahir, and B. Cashmore. 2006. Does certification matter? An analysis of operation-level changes required during the Smartwood certification process in the United States. Forest Policy and Economics 9:197-208.

Newton, I. 1994. The role of nest sites in limiting the numbers of hole-nesting birds, a review. Biological Conservation 70:265-276.

Newton, I. 1998. Population limitation in birds. Academic Press, London, UK.

Nichols, J. D., and B. K. Williams. 2006. Monitoring for conservation. Trends in Ecology and Evolution 21:668-673.

Nowak, R. M. 1999. Walker's mammals of the world. Sixth edition. John Hopkins Press, Baltimore, Maryland, USA.

Oliveira, M. A., A. M. Santos, and M. Tabarelli. 2008. Profound impoverishment of the large-tree stand in a hyper-fragmented landscape of the Atlantic forest. Forest Ecology and Management 256:1910-1917.

Perry, D. A., R. Oren, and S. Hart. 2008. Forest ecosystems. John Hopkins University Press, Baltimore, Maryland, USA.

Pickett, S. T. A. 1989. Space-for-time substitution as an alternative to long-term studies. Pages $110-135$ in G. E. Likens, editor. Long-term studies in ecology: approaches and alternatives. Springer-Verlag, New York, New York, USA. 
Pope, M. L. 2003. A study of the Greater Glider (Petauroides volans) in remnant eucalypt patches surrounded by a softwood plantation matrix. Thesis. The Australian National University, Canberra, A.C.T., Australia.

Pope, M. L., D. B. Lindenmayer, and R. B. Cunningham. 2004. Patch use by the greater glider (Petauroides volans) in a fragmented forest ecosystem. I. Home range size and movements. Wildlife Research 31:559-568.

Putz, F. E., P. Sist, T. Fredricksen, and D. Dykstra. 2008. Reduced-impact logging: challenges and opportunities. Forest Ecology and Management 256:1427-1433.

Ranius, T., M. Niklassson, and N. Berg. 2009. Development of tree hollows in pedunculate oak (Quercus robur). Forest Ecology and Management 257:303-310.

Raphael, M. G., and M. L. Morrison. 1987. Decay and dynamics of snags in the Sierra Nevada, California. Forest Science 33:774-783.

Recher, H. F., J. D. Majer, and S. Ganesh. 1996. Eucalypts, arthropods and birds: On the relation between foliar nutrients and species richness. Forest Ecology and Management 85:177-196.

Rose, C., B. G. Marcot, T. K. Mellen, J. L. Ohmann, K. Waddell, D. Lindley, and B. Schreiber. 2001. Decaying wood in Pacific Northwest forests: concepts and tools for habitat management. Pages 580-623 in D. Johnson and T. O'Neil, editors. Wildlife-habitat relationships in Oregon and Washington. Oregon State University Press, Corvallis, Oregon, USA.

Schneider, D. C. 1994. Quantitative ecology. temporal and spatial scaling. Academic Press, San Diego, California, USA

Schwarz, G. 1978. Estimating the dimension of a model. Annals of Statistics 6:461-464.

Seebeck, J. H., G. C. Suckling, and M. A. Macfarlane. 1983. Leadbeater's possum-survey by stagwatching. Victorian Naturalist 100:92-97.

Shepherd, K. R. 1957. Some aspects of ringbarking in Alpine Ash stands. Australian Forestry 21:70-75.

Smith, A. P., and D. B. Lindenmayer. 1988. Tree hollow requirements of Leadbeater's Possum and other possums and gliders in timber production ash forests of the Victorian Central Highlands. Australian Wildlife Research 15:347-362.

Smith, A. P., D. B. Lindenmayer, R. J. Begg, M. A. Macfarlane, J. H. Seebeck, and G. C. Suckling. 1989. Evaluation of the stag-watching technique for census of possums and gliders in tall open forest. Australian Wildlife Research 16:575-580.

Smith, A. P., K. A. Nagy, M. R. Fleming, and B. Green. 1982. Energy requirements and turnover in free-living Leadbeater's Possums, Gymnobelideus leadbeateri (Marsupialia: Petauridae). Australian Journal of Zoology 30:737-749.
Smith, C. Y., M. T. Moroni, and I. G. Warkentin. 2009. Snag dynamics in post-harvest landscapes of western Newfoundland balsam-fir-dominated boreal forests. Forest Ecology and Management 258:832-839.

Steffen, W., A. Burbidge, L. Hughes, D. B. Lindenmayer, W. Musgrave, M. Stafford-Smith, and P. Werner. 2009. Australia's biodiversity and climate change. CSIRO Publishing, Melbourne, Victoria, Australia.

Strayer, D. L., J. S. Glitzenstein, C. Jones, J. Kolasa, G. E. Likens, M. McDonnell, G. G. Parker, and S. T. A. Pickett. 1986. Long-term ecological studies: an illustrated account of their design, operation, and importance to ecology. Institute of Ecosystem Studies, Millbrook, New York, USA.

Sutherland, W. J., A. S. Pullin, P. M. Dolman, and T. M. Knight. 2004. The need for evidence-based conservation. Trends in Ecology and Evolution 19:305-308.

Taulman, J. F., K. G. Smith, and R. E. Thill. 1998. Demographic and behavioral responses of southern flying squirrels to experimental logging in Arkansas. Ecological Applications 8:1144-1155.

Tyndale-Biscoe, H. 2005. Life of marsupials. CSIRO Publishing, Melbourne, Victoria, Australia.

Vanderwel, M. C., J. R. Malcolm, and S. C. Mills. 2007. A meta-analysis of bird responses to uniform partial harvesting across North America. Conservation Biology 5:1230-1240.

van Pelt, R. 2007. Identifying mature and old forests in Western Washington. Washington State Department of Natural Resources, Olympia, Washington, USA.

Venturieri, G. C. 2009. The impact of forestry exploitation on Amazonian stingless bees. Genetics and Molecular Research $8: 684-689$

Walker, B. H., and D. Salt. 2006. Resilience thinking. Island Press, Washington, D.C., USA.

Welsh, A. H., R. B. Cunningham, and R. L. Chambers. 2000. Methodology for estimating the abundance of rare animals: seabird nesting on North East Herald Cay. Biometrics 56:2230.

Whelan, R. J. 1995. The ecology of fire. Cambridge University Press, Cambridge, UK.

Wiens, J. A. 1981. Single-sample surveys of communities: are the revealed patterns real? American Naturalist 117:90-98.

Wiens, J. A. 1989. The ecology of bird communities. Volume 2. Processes and variations. Cambridge University Press, Cambridge, UK.

Wood, S. W., Q. Hua, K. J. Allen, and D. M. J. S. Bowman. 2010. Age and growth of a fire prone Tasmanian temperate old-growth forest stand dominated by Eucalyptus regnans, the world's tallest angiosperm. Forest Ecology and Management 260:438-447.

\section{APPENDIX}

Tables showing data on and models for numbers of arboreal marsupials in montane ash forests per site, abundance of species, species richness, and probability of observing an animal in an individual tree with hollows (Ecological Archives M081-020-A1).

\section{DATA AVAILABILITY}

Data associated with this paper have been deposited in Dryad: http://dx.doi.org/10.5061/dryad.qp1f6h0s 